\title{
Coupled Thermal and Water Management in Polymer-Electrolyte Fuel Cells
}

\author{
Adam Z. Weber ${ }^{1, *, z}$ and John Newman ${ }^{1,2, * *}$ \\ ${ }^{1}$ Lawrence Berkeley National Laboratory, Berkeley, California 94720 \\ ${ }^{2}$ Department of Chemical Engineering, \\ University of California, Berkeley, California 94720-1462, USA
}

Thermal and water management are intricately coupled in polymer-electrolyte fuel cells. In this paper, we simulate fuel-cell performance and account for nonisothermal phenomena. The transport of water due to a temperature gradient and its associated effects on performance are described, with the increase of reactant dilution by the water-vapor partial pressure being the most dominant. In addition, simulations are undergone to find the optimum operating temperature and maximum power density as a function of external heat-transfer coefficient. The shape of the optimization curves and the magnitudes of the nonisothermal phenomena are also detailed and explained.

* Electrochemical Society Member

** Electrochemical Society Fellow

z E-mail: azweber@lbl.gov 


\section{Introduction}

It is well known and documented that knowledge of water management is critical in optimizing and understanding polymer-electrolyte fuel-cell (PEFC) behavior. What is sometimes ignored is the interplay between thermal and water management. An example effect is a heat pipe, as shown in Figure 1. In the figure, a temperature gradient induces phase-change and net mass-transfer of water. Hence, water is evaporated in the cathode catalyst layer due to the heat of reaction and moves in the vapor phase down the temperature gradient. The water condenses as it moves along the gradient due to the change in vapor pressure with temperature. Obviously, the heat-pipe effect is more significant at higher temperatures and with larger gradients due to the change in water vapor pressure with temperature. In addition to the aspect mentioned above, nonisothermal operation and effects have various pros and cons on PEFC behavior, which must be accounted for in any type of model. Examples of such phenomena include the following changes with increasing temperature: decreased theoretical potential, increased amount of gas dilution by water vapor, enhanced gas crossover, increased value of the various transport and kinetic parameters, and lower membrane water content. The above issues are becoming increasingly important as higher operating temperatures, lower inlet humidities, and larger current densities are being realized in PEFCs.

Due to experimental difficulties, mathematical simulations are ideally suited to analyzing PEFC thermal and water behavior. While there have been various nonisothermal models over the last decade, it is only recently that such models have begun to analyze temperature gradients and distributions within the through-plane or fuel-cell-sandwich direction and under more stateof-the-art operating conditions. ${ }^{1-5}$ Of these, many are of the one-phase variety and thus unable to explore the interrelation between thermal gradients and water management. In this paper, this 
aspect is presented in detail including how overall PEFC fuel-cell performance is impacted. Specifically, nonisothermal, one-dimensional fuel-cell-sandwich simulations are run under different thermal scenarios, and the resulting polarization curves and maximum power densities are compared and explained.

The early nonisothermal models (see, for example, Fuller and Newman ${ }^{6}$ ) assumed that the fuel-cell sandwich remains isothermal due to its thinness, but heat is evolved due to efficiency losses in the sandwich. Such a treatment allows for examination of temperature changes along the gas channel. This analysis can be done by using a simple energy balance in the form of ${ }^{7,8}$

$$
Q=i\left(U_{H}-V\right)
$$

where $Q$ is the total heat generated per superficial area, $i$ is the superficial current density, $V$ is the (observed) cell potential, and $U_{H}$ is the enthalpy potential for the fuel-cell reaction,

$$
U_{H}=\frac{\Delta H}{2 F}=U^{\theta}-T \frac{\partial U^{\theta}}{\partial T}
$$

where $T$ is the absolute temperature, $F$ is Faraday's constant, and $U^{\theta}$ is the standard cell potential, $1.229 \mathrm{~V}$ at $25^{\circ} \mathrm{C}$. The problem with this analysis is that it ignores the exact location of heat generation, energy transport, and the impact of temperature gradients in the sandwich. The assumption of isothermal operation in the PEFC sandwich breaks down as larger current densities are realized (see equation 1), and has been shown both through modeling ${ }^{2-5}$ and experimentation $^{9,10}$ to be erroneous under typical operating conditions. Furthermore, due to the exponential nature of the water vapor pressure, a temperature gradient of a few degrees can cause changes in transport in the PEFC, especially at higher temperatures. These points are discussed in more detail in a later section. 
The structure of this paper is as follows. First, the model is described, with emphasis on the energy balance. Next, the results and discussion are given and separated into three subsections. The first subsection deals with overall impacts of nonisothermal operation and contains some optimization results. The second subsection examines a case study and focuses on the effects of the temperature gradient. The third subsection deals with a couple of possible mitigation strategies to reduce the effect of the performance-limiting nonisothermal phenomena. Finally, some conclusions are outlined.

\section{Fuel-Cell Model}

The modeling domain for this study is the 1-D PEFC sandwich composed of five main layers: the membrane (Nafion $\left.{ }^{\circledR} 112\right)$, anode catalyst layer (aCL) and gas-diffusion layer (aGDL), and a cathode catalyst layer (cCL) and gas-diffusion layer (cGDL). The GDLs and pore properties of the CLs are taken to be symmetric for simplicity with thicknesses of $250 \mu \mathrm{m}$ and 20 $\mu \mathrm{m}$ for the GDLs and CLs, respectively. In addition there are also the anode and cathode gas channels, but these are used only for the boundary conditions for the 1-D sandwich, as detailed below. Finally, it is assumed that the outsides of the gas-channel plates are in contact with coolant streams that remain at a fixed temperature (i.e., there is a large coolant flow). Other assumptions are steady-state operation, negligible gravity, local equilibrium (e.g., temperature is the same in all phases at a given location), and liquid water product.

The simulations utilize and build on our previous models, and the reader is referred to references ${ }^{11-13}$ for detailed discussions on the modeling approaches, equations, and parameter expressions as well appropriate historical references. In short, the membrane is treated using our hybrid approach that accounts for transport in both liquid- and vapor-equilibrated membranes for 
both water and protons. ${ }^{11}$ It utilizes concentrated-solution theory and a combined driving force for water movement. The CLs are treated using a combined agglomerate-and-porous-electrode approach along with the membrane and GDL models. ${ }^{12}$ The GDLs are treated using our cut-andrejoin bundle-of-capillaries approach with separate hydrophobic and hydrophilic domains. ${ }^{13}$ Liquid flow is modeled using Darcy's law, and gas flow is done with Stefan-Maxwell and Knudsen diffusion along with Darcy's law. Unlike in our previous simulations, the gas phase is not assumed to be isobaric (i.e., the gas permeability is finite). Furthermore, due to the intimate contact between phases, water vapor is assumed to be in equilibrium with the liquid water if present.

In terms of modeling nonisothermal effects, the first requirement is to have the proper temperature dependences for all of the transport, material, physical, kinetic, etc. properties. These have all been given previously in the above referenced publications. The only properties explicitly given in this paper are those in Table I, which summarizes properties required specifically for nonisothermal phenomena. It should be noted that while it is known that GDLs have anisotropic material properties, this is neglected in a 1-D simulation; this point will be discussed in more detail in the results and discussion section. The second requirement is to alter any of the governing equations to account for nonisothermal effects. Fortuitously, this does not require any explicit modifications since it is assumed that thermal diffusion, the Dufour effect, heats of mixing, and temperature gradients within the CL agglomerates are negligible. ${ }^{1}$ Furthermore, the driving forces used in the governing equations remain the same because of the cancellation of the partial molar entropy term in the generalized driving force due to the GibbsDuhem equation. ${ }^{1,19}$ Finally, we are currently investigating possible thermo-osmosis in the membranes, ${ }^{20}$ but it is neglected in this work. 
The final requirement is to include an energy balance. For PEFCs, this governing equation under steady-state operation has the form ${ }^{18,19}$

$$
\sum_{g} \rho_{g} \hat{C}_{p_{g}} \mathbf{v}_{g} \cdot \nabla T-\nabla \cdot\left(k^{\text {eff }} \nabla T\right)=\sum_{g} \frac{\mathbf{i}_{g} \cdot \mathbf{i}_{g}}{\kappa_{g}^{\text {eff }}}+\Delta H_{\text {vap }} r_{\text {cond }}+\sum_{h} i_{h}\left(\eta_{h}+\Pi_{h}\right)
$$

where it has been assumed that the temperatures in the various phases (i.e, membrane, gas, liquid, and solid) are in equilibrium with each other. The first term on the left side basically is the transport of enthalpy, where $\hat{C}_{p_{g}}, \rho_{g}$, and $\mathbf{v}_{g}$, are the (average) heat capacity, density, and mass-averaged velocity of phase $g$, respectively. The second term on the left side represents heat transfer due to conduction, where $k^{\text {eff }}$ is the effective thermal conductivity of the system and the values for the different layers are given in Table I. Rigorously, the effective thermal conductivity should be some combination of the individual phase conductivities. For example, the membrane thermal conductivity should be a function of its water volume fraction. The correct mathematical calculation for the effective thermal conductivity is currently under investigation.

The right side of equation 3 represents the heat generation and consumption terms. The first term is Joule or ohmic heating, where $\kappa_{g}^{\text {eff }}$ is the effective electrical conductivity of phase $g$. The second term is due to evaporation/condensation of water, where $\Delta H_{\text {vap }}$ is the heat of vaporization and $r_{\text {cond }}$ is the rate of condensation. As mentioned above, equilibrium is assumed among water vapor and liquid water (if present). However, there can still be movement of water from the vapor phase to the liquid phase or, in other words, the volume fraction of water in the respective phases can change. A relevant example is that if the temperature decreases, then water will condense from the vapor phase, but still be in equilibrium with the liquid phase. To account for 
this significant heat interaction, the mass balance of water vapor is used to calculate how much water has condensed. This is done in accordance with the assumption of equilibrium, and the analysis is similar to using a lever-arm rule along the water phase diagram. In addition to vapor to liquid phase transitions, $r_{\text {cond }}$ is also used for the transfer of water vapor to and from the membrane in the catalyst layers. The reason is that water in the membrane is assumed to be in a condensed state with the same heat of vaporization as pure water.

The final term on the right side is generation due to the electrochemical reactions, where $i_{h}$, $\eta_{h}$, and $\Pi_{h}$ are the transfer current, overpotential, and Peltier coefficient of reaction $h$, respectively. The overpotential represents heat generation due to irreversible operation (i.e., efficiency losses), and the Peltier coefficient represents the reversible heat generation, ${ }^{21}$ and can be thought of as ${ }^{18}$

$$
\Pi_{h}=T \frac{\Delta S_{h}}{n_{h} F}
$$

where $\Delta S_{h}$ and $n_{h}$ are the entropy of reaction and number of electrons transferred in half-cell reaction $h$, respectively, and $F$ is Faraday's constant. The Peltier coefficient for the hydrogenoxidation reaction (HOR) has been measured experimentally, ${ }^{22-24}$ and an average value of -13 $\mathrm{mV}$ at $25^{\circ} \mathrm{C}$ is used. The oxygen-reduction reaction (ORR) coefficient is calculated by using equation 4 and the entropy change for the overall reaction, ${ }^{16}$

$$
\Pi_{\mathrm{HOR}}+\Pi_{\mathrm{ORR}}=T \frac{\Delta S}{2 F}
$$

This calculation results in $\Pi_{\mathrm{ORR}}=-240 \mathrm{mV}$ at $25^{\circ} \mathrm{C}$. This value agrees well with that of Shibata et $a .^{25}$ Direct experimental measurement of Peltier coefficients is more reliable and rigorous 
than trying to determine the entropy change for the half reaction, which is not truly a measurable quantity. However, the above values do agree fairly well with those of Lampinen et al., ${ }^{26}$ which are often used in fuel-cell modeling. Finally, from the above values it is readily apparent that almost all of the reversible heat is generated on the cathode due to the oxygen-reduction reaction.

For internal boundary points, superficial fluxes and interstitial concentrations are continuous. For the membrane, the rate equations transfer water between the membrane and the liquid and gas phases. The ionic current density is zero at the GDL/CL interfaces, the electronic current density is zero at the membrane/CL interfaces, the electric potential is set equal to zero (arbitrary reference) at the aGDL/aGC interface, and the potential is set to the operating potential at the cGDL/cGC interface. For the mass-balance and transport equations, boundary conditions are required at each GC, as described below. For the energy balance, equation 3, two temperature boundary conditions are required since it is a second-order equation in temperature. The appropriate conditions are the temperatures in the cGC and aGC.

To determine the appropriate conditions in the GCs, simultaneous mass and energy balances are solved in the gas channel as shown schematically for the cathode in Figure 2. The top and bottom arrows signify the cell inlets and outlets, respectively. The right inlets/outlets are to/from the cGDL. Generation or consumption of heat can also occur, including water phase change. Finally, heat is also removed from the cell to the external coolant stream using a simple heattransfer equation,

$$
Q=h\left(T-T_{\text {cool }}\right)
$$

where $h$ is the heat-transfer coefficient per superficial area to the coolant stream, and $T_{\text {cool }}$ is the coolant-stream temperature. 
In terms of the mathematical formulation, the mass- and energy-balance boundary conditions for the cGC can be expressed as the following series of coupled equations

$$
\begin{aligned}
& \mathrm{O}_{2}: \quad y_{\mathrm{O}_{2}}=1-y_{\mathrm{H}_{2} \mathrm{O}}-y_{\mathrm{N}_{2}} ; \quad \mathbf{N}_{\mathrm{O}_{2}}=\frac{0.21 \lambda_{\text {air }} I}{4 F}+\left.\mathbf{N}_{\mathrm{O}_{2}}\right|_{\mathrm{cGDL}} \\
& \mathrm{N}_{2}: \quad y_{\mathrm{N}_{2}}=0.79\left(1-y_{\mathrm{H}_{2} \mathrm{O}}\right), \quad \mathbf{N}_{\mathrm{N}_{2}}=\frac{0.79 \lambda_{\text {air }} I}{4 \mathrm{~F}} \\
& \mathrm{H}_{2} \mathrm{O}_{(\mathrm{G})}:\left\{\begin{array}{cc}
y_{\mathrm{H}_{2} \mathrm{O}}=\frac{p_{\mathrm{H}_{2} \mathrm{O}}^{\text {vap }}}{p_{\mathrm{G}}} ; \quad \mathbf{N}_{\mathrm{H}_{2} \mathrm{O}, \mathrm{G}}=\left(\mathbf{N}_{\mathrm{O}_{2}}+\mathbf{N}_{\mathrm{N}_{2}}\right) \frac{y_{\mathrm{H}_{2} \mathrm{O}}}{1-y_{\mathrm{H}_{2} \mathrm{O}}} & \text { for } p_{\mathrm{L}} \geq p_{\mathrm{G}} \\
\mathbf{N}_{\mathrm{H}_{2} \mathrm{O}, \mathrm{G}}=\left.\mathbf{N}_{\mathrm{H}_{2} \mathrm{O}, \mathrm{G}}\right|_{\mathrm{cGDL}}+\left.\mathbf{N}_{\mathrm{H}_{2} \mathrm{O}, \mathrm{L}}\right|_{\mathrm{cGDL}}+y_{\mathrm{H}_{2} \mathrm{O}}^{\text {in } \frac{\lambda}{\text { air }} I}-\mathbf{N}_{\mathrm{H}_{2} \mathrm{O}}^{\text {cond }} ; & \text { for } p_{\mathrm{L}}<p_{\mathrm{G}} \\
y_{\mathrm{H}_{2} \mathrm{O}}=\frac{\mathbf{N}_{\mathrm{H}_{2} \mathrm{O}, \mathrm{G}}}{\mathbf{N}_{\mathrm{O}_{2}}+\mathbf{N}_{\mathrm{N}_{2}}+\mathbf{N}_{\mathrm{H}_{2} \mathrm{O}, \mathrm{G}}} &
\end{array}\right. \\
& \mathrm{H}_{2} \mathrm{O}_{(\mathrm{L})}: \begin{cases}p_{\mathrm{L}}=p_{\mathrm{G}} ; \quad \mathbf{N}_{\mathrm{H}_{2} \mathrm{O}, \mathrm{L}}=\left.\mathbf{N}_{\mathrm{H}_{2} \mathrm{O}, \mathrm{L}}\right|_{\mathrm{cGDL}}+\mathbf{N}_{\mathrm{H}_{2} \mathrm{O}}^{\text {cond }} & \text { for } p_{\mathrm{L}} \geq p_{\mathrm{G}} \\
\left.\mathbf{N}_{\mathrm{H}_{2} \mathrm{O}, \mathrm{L}}\right|_{\mathrm{cGDL}}=0 ; \quad \mathbf{N}_{\mathrm{H}_{2} \mathrm{O}, \mathrm{L}}=\mathbf{N}_{\mathrm{H}_{2} \mathrm{O}}^{\text {cond }} \mid & \text { for } p_{\mathrm{L}}<p_{\mathrm{G}}\end{cases} \\
& T: \quad Q=-\left.k^{\text {eff }} \Delta T\right|_{\mathrm{cGDL}}+\mathbf{N}_{\mathrm{H}_{2} \mathrm{O}}^{\text {cond }} \Delta H_{\text {vap }}+H_{\mathrm{G}}^{\text {in }}\left(\frac{\lambda_{\text {air }} I}{4 F} \frac{1}{1-y_{\mathrm{H}_{2} \mathrm{O}}^{\text {in }}}\right)-H_{\mathrm{G}}\left(\mathbf{N}_{\mathrm{O}_{2}}+\mathbf{N}_{\mathrm{N}_{2}}+\mathbf{N}_{\mathrm{H}_{2} \mathrm{O}, \mathrm{G}}\right) \\
& +\left.H_{\mathrm{G}}\right|_{\mathrm{cGDL}}\left(\left.\mathbf{N}_{\mathrm{H}_{2} \mathrm{O}, \mathrm{G}}\right|_{\mathrm{cGDL}}+\left.\mathbf{N}_{\mathrm{O}_{2}}\right|_{\mathrm{cGDL}}\right)-H_{\mathrm{L}}\left(\mathbf{N}_{\mathrm{H}_{2} \mathrm{O}, \mathrm{L}}-\left.\mathbf{N}_{\mathrm{H}_{2} \mathrm{O}, \mathrm{L}}\right|_{\mathrm{cGDL}}\right)
\end{aligned}
$$

where $\lambda_{\text {air }}$ is the air stoichiometry, I is the total current density, $\left.\mathbf{N}_{i}\right|_{\mathrm{cGDL}}$ denotes the flux of species $i$ coming from the 1-D simulation (i.e., one the cGDL side of the cGDL/cGC interface), $y_{i}$ is the gas-phase mole fraction of species $i, p_{k}$ is the total pressure of phase $k, \mathbf{N}_{\mathrm{H}_{2} \mathrm{O}}^{\mathrm{con}}$ is the mass of water that condenses in the cGC, $H_{k}$ is the molar enthalpy of phase $k$, which can be calculated from its composition and handbook values, ${ }^{16,17}$ and the superscript "in" means the inlet to the channel (see Figure 2). Typically, the concentrations are linearly averaged between their inlet and outlet values, although this is not shown in the above equations for brevity, which ensures that the energy and mass balances account for flow stoichiometry and gas composition changes down the channel correctly. The set of boundary conditions for the aGC/aGDL 
interface is essentially the same as equation 7, except that the directions of the fluxes from the aGDL will have the opposite sign as those from the cGDL, and since pure hydrogen is used, there is no equation for the inert (i.e., no $\mathrm{N}_{2}$-type equations). We believe that equation 7 is the best way to handle the water, gas, and thermal interactions in the GCs without doing a full-blown model for them. In the above formulation, the physical condition that only water with a pressure greater than the ambient GC gas pressure is used. If one assumes that hydrophilic pores exist in the GDL, then this condition determines that there is a finite liquid saturation (equal to the fraction of hydrophilic pores) at the cGDL/cGC interface when liquid water flows from the cGDL. Equation 7 also is similar to a Danckwerts-Wehner-Whelhelm ${ }^{27}$ condition that ensures that more water is not brought into the 1-D sandwich than physically possible.

Unless otherwise specified, the simulation conditions are as follows. The feed into the cell is pure hydrogen and air with stoichiometries of 2 and 4, respectively. The feed gases are saturated in order to allow for the use of a 1-D simulation and to emphasize the impact of thermal management on water management. The inlet and operating pressures for the gases are $1 \mathrm{bar}$.

\section{Results and Discussion}

Optimization and general nonisothermal effects.-To examine the impact of the inclusion of nonisothermal phenomena, both isothermal and nonisothermal simulations are run. The resulting polarization curves are shown in Figure 3 for two different temperatures, where the temperature is the operating temperature for the isothermal case and the inlet and coolant temperature for the nonisothermal ones (the average operating cell temperature for the nonisothermal case is higher than for the isothermal case, as will be shown later). Most of the curves demonstrate worse performance when nonisothermal phenomena are included, although the performance approaches 
and may surpass that of the isothermal case as the heat-transfer coefficient increases. This is not surprising since a larger heat-transfer coefficient results in temperatures closer to that of the isothermal case. The reason why the $T=65^{\circ} \mathrm{C}, h=10 \mathrm{~W} / \mathrm{cm}^{2} \mathrm{~K}$ performs better than the isothermal one is that the benefits of higher temperature in terms of increased kinetics and transport properties outweigh the losses due to changes in the water management (e.g., increased vapor pressure). This is not the case for $T=80^{\circ} \mathrm{C}$, due to the exponential nature of the vapor pressure curve.Error! Reference source not found.

The curves in Figure 3 also demonstrate greater deviations in the mass-transfer or lowpotential part of the polarization curve, which is due to the increased heat production and its subsequent effects on water management and mass transfer in general. Again this is much more apparent in the $80^{\circ} \mathrm{C}$ cases, where dilution by water vapor is more significant and consequently so is the mass-transport limitation of oxygen on the cathode side of the PEFC. Figure 3 demonstrates that nonisothermal phenomena are not necessarily detrimental to PEFC performance, and any changes depend on the operating and heat-transfer conditions. As a point of reference, a heat-transfer coefficient of around $1 \mathrm{~W} / \mathrm{cm}^{2} \mathrm{~K}$ is equivalent to conduction through a typical graphite flow-field plate to a coolant stream. Finally, in all of the curves, the cathode limits performance, and the anode overpotentials are minimal due to the fast hydrogen oxidation reaction and the fact that a relatively high stoichiometry, pure hydrogen feed is used.

The above simulations show two temperatures, and one may wonder how sensitive PEFC performance is for a range of operating (i.e., coolant and feed) temperatures. To answer this question, simulations are carried out in which polarization curves are run at different temperatures, and the maximum or peak power is noted, as shown in Figure 4. The maximum power is chosen as the metric for ease of comparison and because it is a meaningful number and 
normally occurs at potentials where mass-transport limitations are becoming significant (typically around $0.45 \mathrm{~V}$ ). Figure 4 demonstrates that, for all cases, the maximum in the maximum power is typically broad, with a relatively steep decline at higher temperatures. Once again, this is typically caused more by reactant dilution by water vapor than any other factor, as witnessed by the fact that the isothermal curve is of a similar shape. However, as will be discussed in detail later, the temperature gradient itself also has a significant influence.

Figure 4 shows that the optimum operating temperature is around $65^{\circ} \mathrm{C}$, unless the heat transfer is poor. For this latter case, the optimum temperature is lower, which offsets the increase in temperature caused by the poor heat transfer. As seen in Figure 3, at higher than the optimum temperature, mass-transport limitations are more severe and offset the gains of transport properties and kinetics at the increased temperatures. This is not the case at lower than optimum temperatures, where the high-temperature benefits outweigh the losses. Under these conditions, the curves approach one another because the temperature profile is similar due to similar heat generation and the fact that the vapor pressure changes with temperature are small and do not cause any additional mass-transport limitations. In other words, the heat removal is not limiting nor is the vapor-pressure change with temperature. One should note that the isothermal case is not the same as an infinite heat-transfer coefficient since the heat removal is only at the boundaries.

The curves in Figure 3 and Figure 4 exhibit better performance as the external heat transfer is increased. However, from an engineering point of view, one may wonder what heat transfer is necessary to obtain good performance. This question can be answered by running optimization simulations similar to those in Figure 4, yet using the heat-transfer coefficient as another optimization metric. The results of this two-parameter optimization are shown in Figure 5. Both 
the resulting maximum power and the temperature at which it occurs are given as a function of the heat-transfer coefficient. Not unexpectedly, and as seen in Figure 4, the optimum operating temperature decreases sharply with decreasing heat-transfer coefficient due to different temperature distributions and temperature increases in the PEFC sandwich. In fact, for the base operating conditions given, a heat-transfer coefficient below $0.2 \mathrm{~W} / \mathrm{cm}^{2} \mathrm{~K}$ was unable to be simulated due to the significant temperature increase and nonlinearities caused by the nonisothermal phenomena. The optimum temperature for the $0.2 \mathrm{~W} / \mathrm{cm}^{2} \mathrm{~K}$ case is $51^{\circ} \mathrm{C}$. While such low heat transfer is not expected to occur in the laboratory due to natural convection, etc., it could occur within a cell in a stack that has improper or poor heat management. As both Figure 4 and Figure 5 demonstrate, such a cell would be operating very poorly. Furthermore, the cell would be much more likely to degrade and have lifetime problems. Even within a single cell, regions of poor heat transfer (e.g., the middle of a full-size cell) may be under nonoptimal conditions, which could result in durability problems such as cell reversal and carbon corrosion. Simulations are ongoing to study how heat transfer and nonisothermal phenomena affect PEFC durability.

The curves in Figure 5 plateau around heat-transfer coefficients of 5 to $10 \mathrm{~W} / \mathrm{cm}^{2} \mathrm{~K}$, which is where the temperature distribution becomes more or less fixed, as seen in Figure 6. As noted above, these values are not too far off the typical state-of-the-art PEFC. This is not too surprising due to the empirical optimization that has been done on these systems; here we provide the mathematical justification for the experimental results. The plateaus in the curves demonstrate that extraordinary heat transfer is not required for optimum performance, with the caveat that the heat transfer is at the sufficient limits throughout the cell and stack. The optimum maximum power in Figure 5 has a relatively narrow range, showing that one quickly obtains 
diminishing returns for better heat transfer, where the only gain is the slight increase in transport in the GDLs. The same can be said for the optimum operating temperature, around 65 to $67^{\circ} \mathrm{C}$. All together, curves such as those in Figure 3, Figure 4, and Figure 5 provide engineering results as to how heat transfer and nonisothermal phenomena affect PEFC performance. For example, operation at higher temperature, which is desired from an automotive standpoint, will require much better heat transfer, pressurized feeds, or a combination of both.

While the previous discussion focuses on the overall and optimum performance, it is instructive to analyze the underlying reasons for the shapes of the curves. One question to be answered is whether dilution by the increased temperature is the main culprit for performance loss. To answer this, we first examine Figure 6, where the anode and cathode gas-channel temperatures and the corresponding temperature drop through the aGDL and cGDL for the $80^{\circ} \mathrm{C}$ cases are shown. It is apparent that there is both a rapid increase in temperature and a decrease in the temperature gradient as the heat-transfer coefficient decreases. Both of these factors impact PEFC water management and performance, and the interplay between the two may be a cause for the optimum seen in Figure 5. In terms of which one is dominant, the results from Figure 6 can be compared to those in Figure 3 and Figure 4, with the conclusion that the dilution due to increased temperature is dominant. To investigate the situation further, the simulations at $80^{\circ} \mathrm{C}$ shown in Figure 3 are analyzed in some more detail and compared to new simulations in which heat generation is accounted for but the PEFC sandwich is taken to be isothermal (i.e., at a uniform temperature). This is a typical assumption that has been used for modeling nonisothermal effects in PEFCs. ${ }^{1}$ The way in which the simulations are run is that equation 1 is used to determine the overall heat generation in the cell. Next, this value is used in an overall heat balance for the cell, which is similar to that shown in Figure 2 except that the heat-transfer 
term replaces the terms on the left side of the schematic since the balance is over the entire sandwich. Figure 7a shows the resulting polarization curves (grey) for this type of simulation at an inlet and coolant temperature of $80^{\circ} \mathrm{C}$ and two heat-transfer-coefficient values; included in the figure are the curves from Figure 3 (black) for comparison.

From the curves it is apparent that while the dilution effect of the higher temperature is the major reason for the performance loss, it is not the only significant one. Hence, the temperature gradient, which is ignored in the simulations where the PEFC sandwich is taken to be isothermal, does have an effect, and one that is expected to become more dominant at higher heat-transfer coefficients where the temperature gradient becomes more severe (see Figure 6). The nature of the temperature-gradient effect is examined in more detail in the next section. Although not shown, a similar analysis at $65^{\circ} \mathrm{C}$ demonstrates the same results and trends except that the dilution effect is more significant than the temperature-gradient one for a given heat-transfer coefficient. The reason is due to the shape of the water-vapor-pressure curve.

To analyze the interplay between thermal and water management in more detail, Figure $7 \mathrm{~b}$ shows the dimensionless net water flux through the membrane, the so-called $\beta$ value

$$
\beta=\frac{\mathbf{N}_{\mathrm{w}}}{I / F}
$$

It is interesting that only for the isothermal case does $\beta$ increase with current density, signifying an increase in the amount of water that is moving from anode to cathode. The reason for the increase is because the electroosmotic flux increases more than the back flux through the membrane. This is one reason why the membrane dries out at high current densities even though the feeds are saturated. However, for the heat-effect cases, including the ones in which the PEFC sandwich is assumed to be at a uniform temperature, $\beta$ decreases with current density. 
The first explanation might be that $\beta$ decreases with increasing temperatures; however, it is known that $\beta$ actually decreases with decreasing temperature (e.g., $\beta=0.17$ at $65^{\circ} \mathrm{C}$ ), which is mainly due to the decreases in the water vapor pressure with decreasing temperature. ${ }^{28,29}$

There are two main reasons for the decrease in $\beta$. First, the feed gases are entering the cell below the actual cell temperature; consequently, they are slightly under saturated. While they become saturated at the cathode due to water production, this does not happen at the anode because the membrane is not fully hydrated and liquid water does not reach the anode. Furthermore, this effect increases as the current density increases due both to membrane dehydration and more heat generation. Since the anode is slightly subsaturated and the cathode is not, a larger flux of water from cathode to anode results; $\beta$ decreases. ${ }^{29}$ The second reason for the decrease in $\beta$ is that as the temperature increases with current density, the various transport coefficients, especially those in the membrane, increase at a greater rate than the electroosmotic coefficient, thus enabling a larger net back-flux of water.

The above causes are also part of the reason why the full nonisothermal cases demonstrate lower $\beta$ values than those that account for heat generation but have a uniform sandwich temperature. These latter cases result in average temperatures that are below the temperatures in the catalyst layers seen in the rigorous nonisothermal cases (see Figure 6). In other words, the full nonisothermal cases result in higher degrees of subsaturation at the anode, as well as higher membrane temperatures. Obviously, these effects are more pronounced for lower heat-transfercoefficient values. Finally, as seen above and discussed in the next section, the influence of the temperature gradient also has a bearing on the net water flux through the membrane, which is why $\beta$ changes much more significantly for the full nonisothermal cases than for the other cases. 
Overall, Figure 7 clearly demonstrates the interaction between water and thermal management. As more water is moved from anode to cathode, the PEFC performance is worse. This is atypical in terms of expected PEFC trends, where lower $\beta$ values normally signify less cathode flooding and better membrane hydration resulting in lower resistance. In fact, thin membranes and microporous layers are typically used for their abilities to increase the back flux of water in the membrane (lower $\beta$ ). ${ }^{12}$ The reason why this is not the case here is that the lower $\beta$ values result from worse humidification (especially at the anode), and the cathode flooding is partially minimized by the increased temperatures and temperature gradients. The above discussion shows the importance of being able to predict the temperature distribution, especially that in the catalyst layer. Thus, if one knows the catalyst-layer temperatures, one can design systems with either better heat transfer or where the anode feed gases are slightly oversaturated in terms of the feed or operating temperature. While the above analysis and results provide good insight and design parameters, they are somewhat dependent on the operating conditions and material-property values used as examined in a later section.

Temperature-gradient effects and case study.-The previous section demonstrates that thermal and water management are interrelated and affect PEFC performance. To study that in more depth, a case-study condition of $T=80^{\circ} \mathrm{C}, h=0.5 \mathrm{~W} / \mathrm{cm}^{2} \mathrm{~K}$ is chosen. The reason for this choice is that it magnifies the nonisothermal effects (see Figure 4), although the same phenomena exist to a lesser extent for all temperatures and heat-transfer coefficients.

The temperature profile is shown in Figure 8 at $0.2 \mathrm{~V}$ intervals along the polarization curve (see Figure 3 or Figure 7a). The resulting profile is similar both in magnitude and shape to those in the literature..$^{3,5,10}$ The increase in the gas-channel temperature is a direct function of the heat- 
transfer coefficient, as seen in Figure 6. For the anode, this increase is also a function of capillary condensation into the hydrophilic gas pores. Unlike in the cathode, the anode liquid water must come from condensation since the membrane is not fully liquid equilibrated (i.e., liquid water does not enter the anode from the membrane). Before discussing this point further, it is worthwhile to show the breakdown of the various heat generation and transport terms (i.e., the left and right side of equation 3 , respectively).

Table II gives these breakdowns in terms of the percentage of the absolute total amount and the amount of heat generation. For the heat transfer, the average values in each layer are given, where the ones for the gas channels correspond to those used in the boundary conditions. Not surprisingly, the main mode of heat transfer is by conduction. For the boundaries, the dominant heat transfer is to the coolant stream, although there is still an appreciable heat input from the GDLs (i.e., PEFC sandwich). Conduction is most dominant in the membrane, although convection by the water moving through it is still appreciable. The reason why the aGDL has a higher convective portion than the cGDL is mainly due to the heat-pipe effect, resulting in liquid water in part of the aGDL. As Table II shows, convection of heat is not negligible, contrary to the results of Birgersson et al. ${ }^{2}$ The reason why our results deviate is due to a couple of factors. First, we consider the heat-pipe effect and in fact encourage it by simulating saturated feeds. Also, we use both a hydrophilic and hydrophobic pore network. These changes result in more convection because they promote the existence of a liquid phase and, although gas-phase heat convection is relatively small, liquid-phase convection is not. Finally, our values of the thermal conductivities are slightly different.

The second column of Table II shows the breakdown of the various heat-generation terms both in terms of their overall value and percentage of the total heat generation. As expected, the 
ORR is the principal generator of heat representing almost $80 \%$ of the total heat generation, in agreement with other analyses. ${ }^{5}$ Also as expected, the HOR is not a major heat generator, especially the reversible heat, which agrees with the highly reversible nature of the reaction. While ohmic heating is not that large in its overall magnitude, due to its localization to the membrane and catalyst layers (ohmic heating due to electron conduction is essentially negligible), it can have a significant impact. For example, it generates heat in the membrane, resulting in a slight bowing to the membrane temperature profile in Figure 8; this effect will become more pronounced as the membrane becomes drier.

In terms of water evaporation/condensation, for the given simulation conditions, there is a net amount of water condensation in the PEFC sandwich, resulting in a small amount of heat generation. However, if one separates this term into separate evaporation and condensation ones, as seen in Table II, then these two become the prevailing heat consumption and generation terms, respectively. In fact, from the table, one can see that each term has an absolute magnitude that is over 2.5 times that for the total ORR (combining the reversible and irreversible parts).

The above point deserves some further discussion. It shows that the heat-pipe effect carries a lot of energy. First, condensation/evaporation of water vapor to/from the membranes results in a lot of heat generation/consumption. In fact, this accounts for about half of the $2.15 \mathrm{~W} / \mathrm{cm}^{3}$ or so and is directly due to our assumption that water vapor condenses into the membrane with the same of heat of vaporization as pure water (i.e., it condenses). However, the other half is due to evaporation and condensation between liquid water and water vapor, something that is unrelated to our assumption. The evaporation arises from the increased temperatures within the PEFC, thus making the feed gases slightly subsaturated in which the product water can evaporate. The condensation heat results mainly from two sources. First, water condenses due to the reactions 
and capillary condensation. Capillary condensation occurs by the Kelvin effect at the anode since we assume some hydrophilic pores of different radii. Water condenses due to reaction because of the removal of the reactant gases from a saturated stream in the catalyst layers. This is more dominant on the anode because of the pure hydrogen feed, and also because, as hydrogen is reacted nearer the aGDL/aCL interface, there is insufficient ionic current density and electroosmotic flow to remove the water through the membrane; consequently, there is a buildup of liquid water. The second source of condensation is due to the heat-pipe effect, which causes condensation from a saturated vapor stream as the temperature decreases. Overall, the heat effects associated with evaporation and condensation are enormous, although they are relatively balanced. As discussed in the previous section, these effects become diminished as the operating temperature decreases due to the shape of the vapor-pressure curve. Furthermore, these effects (especially evaporation) could become more important when the feed gases are subsaturated, as discussed in the next section.

Evaporation and condensation cause a significant movement of water, mainly through the heat-pipe effect. This phenomenon is the main reason why convective heat transfer is significant in the GDLs. To examine this effect in more detail, the water fluxes in the liquid and vapor phases and the liquid saturation in the aGDL and cGDL for both the nonisothermal case study and the isothermal case are shown in Figure 9. In the figure, the water fluxes are nondimensionalized in the same way as $\beta$ (equation 8 ).

For the aGDL isothermal case, there is no liquid water (see the liquid saturation) and the water vapor moves from gas channel to catalyst layer along with the reactant hydrogen. However, for the nonisothermal case, the water vapor moves away from the catalyst layer (i.e., in the same direction as the temperature gradient in Figure 8), and against the hydrogen flux. 
Furthermore, the decreasing temperature gradient causes condensation of liquid water, which then moves towards the catalyst layer. The reason for this movement is that more water is condensed as the temperature decreases, causing a water pressure gradient that is opposite in sign to the temperature one. The overall picture in the anode is that there is an internal recirculation of water where it moves away from the catalyst layer as vapor, condenses, and moves back as liquid. Finally, Figure $9 \mathrm{~b}$ clearly shows that there is sharp transition where the anode dries out and there is no liquid water. This point is where the resulting capillary pressure (liquid minus gas pressure) is insufficient to enter the GDL pores, and hence the water must be carried only in the vapor phase.

The cGDL results in Figure 9 exhibit similar phenomena to the aGDL ones. For the isothermal case, water vapor moves toward the catalyst layer (negative direction) with the reactant oxygen, and liquid water moves away from the catalyst layer due to generation. For the nonisothermal case, the water vapor now moves away from the catalyst layer due to the molefraction gradient generated by the temperature gradient; and the liquid water still moves away from the catalyst layer, but with a smaller flux. This smaller flux is caused by the interplay between water production and condensation down the temperature gradient. As discussed above, the heat-pipe effect results in a liquid-water pressure gradient of opposite direction to the temperature gradient. But in the cGDL, this is counteracted by the pressure gradient due to water formation, which is largest near the catalyst layer, resulting in the shape and magnitude of the curve in Figure 9. Therefore, for the cGDL, there is a reverse of the water-vapor flux direction, but not a true recirculating flow. Finally, due to the aforementioned interplay, inclusion of nonisothermal phenomena results in less flooding in the cGDL as clearly seen in its lower saturation in Figure $9 b$. 
Figure 9 demonstrates that temperature gradients significantly alter the water fluxes in a PEFC. This observation also provides one of the answers as to why accounting for the temperature gradient results in worse performance as seen in Figure 7a. The reason is that now the reactant gases have to diffuse and move against a water-vapor gradient, whereas for the uniform-temperature case, the water moves with the reactant gases. Thus, the water-vapor gradient now results in a larger mass-transfer limitation even with the lower cGDL saturation (see Figure 9b); the polarization curves demonstrate worse performance. In fact, the temperature gradient and resulting water-vapor flux may even cause a reversal of the gas flow, resulting in a convective flow of gas out of the GDL and into the gas channel, as has been mentioned as a possibility before. ${ }^{30}$

To examine this issue, the gas-phase mass-averaged velocities are calculated and shown in Figure 10. For the aGDL, a flow reversal occurs after the current density is high enough to generate a reverse water-vapor flux that is larger than the hydrogen one. In this situation, the incoming hydrogen must diffuse down its mole-fraction gradient against this flow. The point of reversal moves closer to the gas channel at higher current densities, as does the liquid-water dryout point. However, for this simulation, there is no net convective flow into the gas channel, although this can occur under other thermal-management schemes. For the cGDL, flow reversal does not occur, but the gas velocity is retarded due to the reverse water-vapor flux (compare the values to $-0.29 \mathrm{~cm} / \mathrm{s}$ for the isothermal case). The reason that the anode side is more affected than the cathode side is that the only other gas in the anode is hydrogen, which has a much lower molecular weight than water, versus air in the cathode, which has a higher molecular weight than water. The flow reversal is also dependent on the concentration of water vapor, and thus is a function of cell operating temperature and feed-gas pressure. 
Mitigation of temperature-gradient effects.-The previous sections demonstrate that temperature gradients and thermal management can affect performance and water distribution and fluxes. In this section, different mitigation strategies and the impact of the nonisothermal phenomena under different operating conditions is considered. As noted above, the thermal conductivity of the GDLs is a quantity that is not known precisely and is under investigation. Figure 11 shows the impact of varying the GDL thermal conductivity over three orders-ofmagnitude. The baseline curves correspond to those given in Figure 3, and the GDL thermal conductivity was increased and decreased by a factor of 10 from the baseline value of 0.015 $\mathrm{W} / \mathrm{cmK}$. Figure 11 demonstrates that the overall performance is not strongly coupled to the change in thermal conductivity, with a change in maximum power of around $5 \%$ for a decade decrease in the thermal conductivity. Furthermore, as expected, the deviations occur more strongly in the mass-transport regime, where the heat generation is higher and the influence of the thermal gradients greater. Similarly, the sensitivity to the thermal conductivity becomes greater as the heat-transfer coefficient is decreased and the temperature is increased (e.g., a $25 \%$ deviation per decade decrease is seen for the $80^{\circ} \mathrm{C}, h=0.5 \mathrm{~W} / \mathrm{cm}^{2} \mathrm{~K}$ case).

The trend in Figure 11 is interesting in that the $0.0015 \mathrm{~W} / \mathrm{cmK}$ case demonstrates greater performance than the $0.15 \mathrm{~W} / \mathrm{cmK}$ case. This is not necessarily expected since the lower the thermal conductivity, the larger the thermal gradients in the system. However, as the GDL thermal conductivity is decreased, the low membrane thermal conductivity ceases to become an obstacle to heat transfer, thus allowing more heat to exit through the aGC. This has the effect of actually decreasing the average temperature and hence the amount of reactant dilution in the cGDL. The lower thermal conductivities also increase the maximum temperature and therefore 
enhance the reaction rates. Finally, the heat-pipe effect also becomes more efficient with the lower thermal conductivities since more heat is moving out by convection than conduction. A detailed analysis of the effect of thermal conductivities is beyond the scope of this paper, and Figure 11 is given as a representative sensitivity analysis.

From the analysis in the preceding sections, temperature gradients can retard reactant movement, and higher temperatures can cause reactant dilution. To counteract these negative aspects, the overall pressure of the gas phase can be increased. This is investigated and shown in Figure 12. As can be seen, the higher pressures result in better performance, as well as cases wherein the nonisothermal performance is better than the isothermal one. The main reason is that now the higher-temperature advantages outweigh the higher-temperature disadvantages. Figure 12 also demonstrates that with pressurized feeds, the optimum operating temperature will be higher since reactant dilution is not as significant. Of course, from a system perspective, pressurizing feeds represents a parasitic power loss.

Finally, PEFCs can also be run with subsaturated feed gases in order to simplify system complexity and cost, and increase performance due to less reactant dilution, especially for the cathode. To investigate this issue preliminarily, a pseudo 2-D, coflow model is developed where the 1-D sandwich model is run along the gas channel. The only changes to the code are that the outputs from one 1-D section are the inputs for the next 1-D section in terms of the boundary conditions expressed in equation 7. Thus, the composition, temperature, and flow rates change along the channel. Figure 13 shows the results of a simulation where both the anode and cathode are fed at $50 \%$ relative humidity at $65^{\circ} \mathrm{C}$. Three temperatures are given, which are the aGC, $\mathrm{cCL}$, and cGC (see Figure 8). Furthermore, the spike in the temperatures in Figure 13 is directly correlated with the formation of liquid water at the cathode since it occurs at the same position as 
when the water-vapor mole fraction reaches its vapor-pressure value (not shown). Before the liquid-water formation, the 1-D sandwich is essentially isothermal, and it is only with liquid water and saturated gases that significant temperature gradients, such as those analyzed in the preceding sections, develop. The main reason is that without liquid water, there is not a significant amount of energy transfer in terms of evaporation and condensation, and more

importantly, the heat generated by the ORR is consumed by evaporating the produced condensed water (i.e., water can be interpreted as being generated as vapor). The temperatures decrease after the liquid water is formed because of the lower amount of heat generated since the current density along the channel decreases. Overall, the above-treated nonisothermal phenomena are not important unless the gases are, or nearly are, saturated.

\section{Conclusions}

To understand and investigate the coupling between thermal and water management, nonisothermal 1-D simulations were run with saturated feed gases. The simulations demonstrated the need to incorporate nonisothermal effects into fuel-cell modeling, especially if the feed gases are saturated, of if they will become saturated within the cell. Even though the fuel-cell sandwich is relatively thin, a temperature gradient of a few degrees can exist across it. This gradient is sufficient to cause a heat-pipe effect where water is evaporated near the catalyst layers and moves and condenses down the temperature gradient towards the gas channels. This movement of water reduces the reactant-gas mass transport to reach the catalyst layers. It also results in more water moving from cathode to anode than for the similar isothermal case. However this lower membrane water flux is also caused by the higher temperature and lack of liquid water in the anode catalyst layer, resulting in a slight amount of subsaturation. 
While the heat-pipe effect is important, the dominant issue in fuel cells is simply the impact of having higher temperatures. These temperatures can be beneficial to performance through increased kinetics and mass transport or detrimental through reactant dilution by water vapor. Which effect is dominant is mainly due to the thermal management and the operating temperature and pressure, where the exponential shape of the water vapor-pressure curve causes significantly more dilution at higher temperature. The optimum operating temperature for a typical cell running at $1 \mathrm{bar}$ with saturated feeds was determined to be around $65^{\circ} \mathrm{C}$, assuming that there is decent heat removal (on the order of $20 \mathrm{~W} / \mathrm{cm}^{2}$ ). This optimum temperature will increase with gas pressure and/or with subsaturated feeds, although the latter also results in tradeoffs in terms of increased ohmic drops.

\section{Acknowledgments}

This research has been supported by the Assistant Secretary for Energy Efficiency and Renewable Energy, Office of Hydrogen, Fuel Cell, and Infrastructure Technologies, of the U. S. Department of Energy under contract number DE-AC02-05CH11231 


\section{List of Symbols}

\section{Roman}

$\hat{C}_{p_{g}}$ heat capacity of phase $g, \mathrm{~J} / \mathrm{gK}$

F Faraday's constant, 96487 C/equiv

$h$ heat-transfer coefficient to coolant stream, W/cm ${ }^{2} \mathrm{~K}$

$H_{k}$ molar enthalpy of phase $k, \mathrm{~J} / \mathrm{mol}$

$\Delta H$ enthalpy change of reaction, $\mathrm{J} / \mathrm{mol}$

$\Delta H_{\text {vap }}$ heat of vaporization of water, $\mathrm{J} / \mathrm{mol}$

$\mathbf{i}_{g} \quad$ superficial current density through phase $g, \mathrm{~A} / \mathrm{cm}^{2}$

$i_{h} \quad$ transfer current for reaction $h, \mathrm{~A} / \mathrm{cm}^{3}$

I magnitude of the total current density, $\mathrm{A} / \mathrm{cm}^{2}$

$k$ thermal conductivity, $\mathrm{W} / \mathrm{cmK}$

$n_{h} \quad$ number of electrons transferred in reaction $h$

$\mathbf{N}_{i} \quad$ superficial flux density of species $i, \mathrm{~mol} / \mathrm{cm}^{2} \mathrm{~s}$

$p_{k} \quad$ total pressure of phase $k$, bar

$P_{\max }$ maximum or peak power, $\mathrm{W} / \mathrm{cm}^{2}$

Q heat flux, $\mathrm{W} / \mathrm{cm}^{2}$

$r_{\text {cond }}$ rate of condensation of water, $\mathrm{mol} / \mathrm{cm}^{3} \mathrm{~s}$

$R \quad$ universal gas constant, $8.3143 \mathrm{~J} / \mathrm{mol} \mathrm{K}$

$\Delta S_{h}$ entropy change of reaction $h, \mathrm{~J} / \mathrm{mol}-\mathrm{K}$

$T$ absolute temperature, $\mathrm{K}$

$U^{\theta} \quad$ theoretical cell potential, $\mathrm{V}$ 
$U_{H}$ enthalpy potential, $\mathrm{V}$

$y_{i} \quad$ gas-phase mole fraction of species $i$

\section{Greek}

$\beta \quad$ net flux of water per proton flux through the membrane

$\Pi_{h}$ Peltier coefficient for charge-transfer reaction $h, \mathrm{~V}$

$\lambda_{i} \quad$ feed stoichiometry of species $i$

$\rho_{g} \quad$ density of phase $g, \mathrm{~g} / \mathrm{cm}^{3}$

$\eta_{h} \quad$ overpotential of reaction $h, \mathrm{~V}$

$\kappa$ conductivity, $\mathrm{S} / \mathrm{cm}$

\section{Superscripts}

eff effective property, corrected for porosity and tortuosity

in fuel-cell inlet conditions 


\section{References}

1. A. Z. Weber and J. Newman, Chemical Reviews, 104, 4679 (2004).

2. E. Birgersson, M. Noponen, and M. Vynnycky, J. Electrochem. Soc., 152, A1021 (2005).

3. J. Ramousse, J. Deseure, O. Lottin, S. Didierjean, and D. Maillet, J. Power Sources, 145, 416 (2005).

4. Y. Y. Shan and S. Y. Choe, J. Power Sources, 145, 30 (2005).

5. H. Ju, H. Meng, and C. Y. Wang, Int. J. Heat Mass Transfer, 48, 1303 (2005).

6. T. F. Fuller and J. Newman, J. Electrochem. Soc., 140, 1218 (1993).

7. D. M. Bernardi, E. Pawlikowski, and J. Newman, J. Electrochem. Soc., 132, 5 (1985).

8. L. Rao and J. Newman, J. Electrochem. Soc., 144, 2697 (1997).

9. P. J. S. Vie and S. Kjelstrup, Electrochim. Acta, 49, 1069 (2004).

10. H. C. Ju, C. Y. Wang, S. Cleghorn, and U. Beuscher, J. Electrochem. Soc., 152, A1645 (2005).

11. A. Z. Weber and J. Newman, J. Electrochem. Soc., 151, A311 (2004).

12. A. Z. Weber and J. Newman, J. Electrochem. Soc., 152, A677 (2005).

13. A. Z. Weber, R. M. Darling, and J. Newman, J. Electrochem. Soc., 151, A1715 (2004).

14. A. Rowe and X. G. Li, J. Power Sources, 102, 82 (2001).

15. Toray Inc., Gas Diffusion Material Product Information Sheet, (2005).

16. R. H. Perry and D. W. Green, Perry's Chemical Engineers' Handbook 7th ed., J. O. Maloney, Editor, McGraw-Hill, New York (1997).

17. CRC Handbook of Chemistry and Physics 64th ed., R. C. Weast, Editor, CRC Press, Boca Raton, FL (1983).

18. J. Newman and K. E. Thomas-Alyea, Electrochemical Systems 3rd ed., John Wiley \& Sons, New York (2004).

19. R. B. Bird, W. E. Stewart, and E. N. Lightfoot, Transport Phenomena 2nd ed., John Wiley \& Sons, Inc., New York (2002).

20. R. Zaffou, J. Yi, H. R. Kunz, and J. M. Fenton, 208th Meeting of the Electrochemical Society, Los Angeles, Abstract 1019 (2005). 
21. J. N. Agar, in Advances in Electrochemistry and Electrochemical Engineering, P. Delahay, Editor, 3, pp. 32-121, John Wiley \& Sons, New York (1963).

22. M. Kamata, Y. Ito, and J. Onishi, Electrochim. Acta, 32, 1377 (1987).

23. Z. Y. Jiang, J. Zhang, L. J. Dong, and J. H. Zhuang, J. Electronanal. Chem., 469, 1 (1999).

24. S. Shibata and M. P. Sumino, J. Electronanal. Chem., 193, 135 (1985).

25. S. Shibata, M. P. Sumino, and A. Yamada, J. Electronanal. Chem., 193, 123 (1985).

26. M. J. Lampinen and M. Fomino, J. Electrochem. Soc., 140, 3537 (1993).

27. J. F. Wehner and R. H. Wilhelm, Chem. Eng. Sci., 6, 89 (1956).

28. G. J. M. Janssen, J. Electrochem. Soc., 148, A1313 (2001).

29. A. Z. Weber and J. Newman, J. Electrochem. Soc., 151, A326 (2004).

30. K. Promislow, J. Stockie, and B. Wetton, Proc. R. Soc. London, A, 462, 789 (2006). 


\section{Captions}

Figure 1. Schematic representation of a heat pipe on the cathode side of the fuel cell. Water is evaporated in the catalyst layer and moves and condenses down the temperature gradient.

Figure 2. Schematic of the cathode gas channel showing the relevant energy interactions for the temperature boundary condition; the external heat-transfer term is given by equation

6. The top of the diagram corresponds to the fuel-cell inlet, the bottom to the outlet, the left to the 1-D sandwich, and the right to the coolant stream.

Figure 3. Polarization curves for isothermal operation and three cases of nonisothermal operation with different heat-transfer coefficients. The temperatures for (a) and (b) signify the inlet and coolant temperatures.

Figure 4. Maximum power as a function of coolant and feed temperature for an isothermal case and three nonisothermal ones with different heat-transfer coefficients.

Figure 5. Optimum coolant and feed temperature as a function of heat-transfer coefficient. The optimization is done for the optimum maximum power, which is also given in the figure.

Figure 6. Anode and cathode gas-channel temperature (solid) and GDL temperature drop (dashed) as a function of heat-transfer coefficient for coolant and inlet temperatures of $80^{\circ} \mathrm{C}$.

Figure 7. Potential (a) and dimensionless net water flux through the membrane, $\beta$ (b) as functions of current density with coolant and inlet temperatures of $80^{\circ} \mathrm{C}$. The dark lines correspond to the isothermal $\left(T=80^{\circ} \mathrm{C}\right)$ and two nonisothermal cases, and the 
grayed lines correspond to simulations that account for heat generation and assume the sandwich is of uniform temperature (i.e., infinite thermal conductivities).

Figure 8. Temperature distribution through the PEFC sandwich at various cell potentials.

Figure 9. Dimensionless liquid-water (solid) and water-vapor (dashed) fluxes (a) and liquid saturation (b) as a function of position in either the anode or cathode GDL and at a cell potential of $0.2 \mathrm{~V}$. Shown are curves for both the $80^{\circ} \mathrm{C}$ isothermal (gray) and the $h=0.5 \mathrm{~W} / \mathrm{cm}^{2} \mathrm{~K}$ nonisothermal (black) simulations. A positive flux signifies movement from anode to cathode.

Figure 10. Mass-averaged gas-phase velocity as a function of position in either the anode or cathode GDL, and at various cell potentials. A positive value signifies movement from anode to cathode. For reference, the average values for the isothermal case are 0.55 and $-0.29 \mathrm{~cm} / \mathrm{s}$ for the aGDL and cGDL, respectively.

Figure 11. Polarization curves showing the effect of a three-order-of-magnitude change in the GDL thermal conductivities; the other thermal conductivities remain as given in Table I. The temperature is $65^{\circ} \mathrm{C}, h=1 \mathrm{~W} / \mathrm{cm}^{2} \mathrm{~K}$, and the isothermal case is shown as a reference.

Figure 12. Polarization curves at $65^{\circ} \mathrm{C}$ and $h=1 \mathrm{~W} / \mathrm{cm}^{2} \mathrm{~K}$ showing the effect of total gas pressure on performance (anode and cathode pressures are equal).

Figure 13. Maximum and cathode and anode gas-channel temperatures as a function of position along the gas channel (the inlet is on the left) using a pseudo 2-D, coflow model with $50 \%$ relative-humidity feeds. The sharp increase in the temperature is associated with liquid-water formation. 
Table I. Necessary thermal-property values; see references 11, 12, 13 for other property values and expressions.

Table II. Percentage of absolute amount of heat transport (left side of equation 3) or total generation (right side of equation 3) at $T=80^{\circ} \mathrm{C}, h=0.5 \mathrm{~W} / \mathrm{cm}^{2} \mathrm{~K}$, and a cell potential of $0.2 \mathrm{~V}$. 
Table I. Necessary thermal-property values; see references ${ }^{11,12,13}$ for other property values and expressions.

\begin{tabular}{lrl}
\hline \multicolumn{1}{c}{ Parameter } & Value \\
\hline Effective thermal conductivity ${ }^{2-5,9,14,15}$ & 0.015 & $\mathrm{~W} / \mathrm{cmK}$ \\
Gas-diffusion layer & 0.003 & $\mathrm{~W} / \mathrm{cmK}$ \\
Catalyst layer & 1 & $\mathrm{~W} / \mathrm{cmK}$ \\
Flow field & 0.0025 & $\mathrm{~W} / \mathrm{cmK}$ \\
Membrane & $-0.24 \frac{T}{298}$ & $\mathrm{~V}$ \\
ORR Peltier coefficient & $-0.013 \frac{T}{298}$ & $\mathrm{~V}$ \\
& & \\
HOR Peltier coefficient & 4.20 & $\mathrm{~J} / \mathrm{gK}$ \\
Heat capacity at $80^{\circ} \mathrm{C}^{16,17}$ & 1.89 & $\mathrm{~J} / \mathrm{gK}$ \\
Liquid water & 0.931 & $\mathrm{~J} / \mathrm{gK}$ \\
Water vapor & 1.04 & $\mathrm{~J} / \mathrm{gK}$ \\
Oxygen & 14.5 & $\mathrm{~J} / \mathrm{gK}$ \\
Nitrogen & 41700 & $\mathrm{~J} / \mathrm{mol}$ \\
Hydrogen & 1.50 & $\mathrm{~V}$ \\
\hline Heat of vaporization at $80^{\circ} \mathrm{C}^{16,17}$ & & \\
Enthalpy potential at $80^{\circ} \mathrm{C}^{18}$ &
\end{tabular}


Table II. Percentage of absolute amount of heat transport (left side of equation 3) or total generation (right side of equation 3 ) at $T=80^{\circ} \mathrm{C}, h=0.5 \mathrm{~W} / \mathrm{cm}^{2} \mathrm{~K}$, and a cell potential of $0.2 \mathrm{~V}$

\begin{tabular}{|c|c|c|c|}
\hline \multicolumn{2}{|c|}{$\begin{array}{l}\text { Average percentage of total } \\
\text { heat transfer by conduction }\end{array}$} & \multicolumn{2}{|c|}{ Heat generation, $\mathrm{W} / \mathrm{cm}^{3}$ ( $\%$ of total) } \\
\hline $\mathrm{aGC}^{\mathrm{b}}$ & $19 \%$ (cond); $60 \%(Q)$ & Net water phase change & $\begin{array}{ll} & \text { cond: } 2.17 \\
0.027(2.6 \%) & \\
& \text { evap: }-2.14\end{array}$ \\
\hline aGDL & $65 \%$ & ORR (irreversible) & $0.568(55.3 \%)$ \\
\hline $\mathrm{aCL}$ & $63 \%$ & ORR (reversible) & $0.226(22.0 \%)$ \\
\hline Mem & $87 \%$ & HOR (irreversible) & $0.089(8.6 \%)$ \\
\hline $\mathrm{cCL}$ & $49 \%$ & HOR (reversible) & $0.009(0.9 \%)$ \\
\hline cGDL & $80 \%$ & Ohmic heating & $0.109(10.6 \%)$ \\
\hline $\mathrm{cGC}^{\mathrm{b}}$ & $33 \%$ (cond); $37 \%(Q)$ & & \\
\hline
\end{tabular}

\footnotetext{
${ }^{\mathrm{a}}$ the rest is transferred by convection

${ }^{\mathrm{b}}$ cond signifies conduction to the sandwich and $Q$ signifies external heat transfer (equation 7)
} 


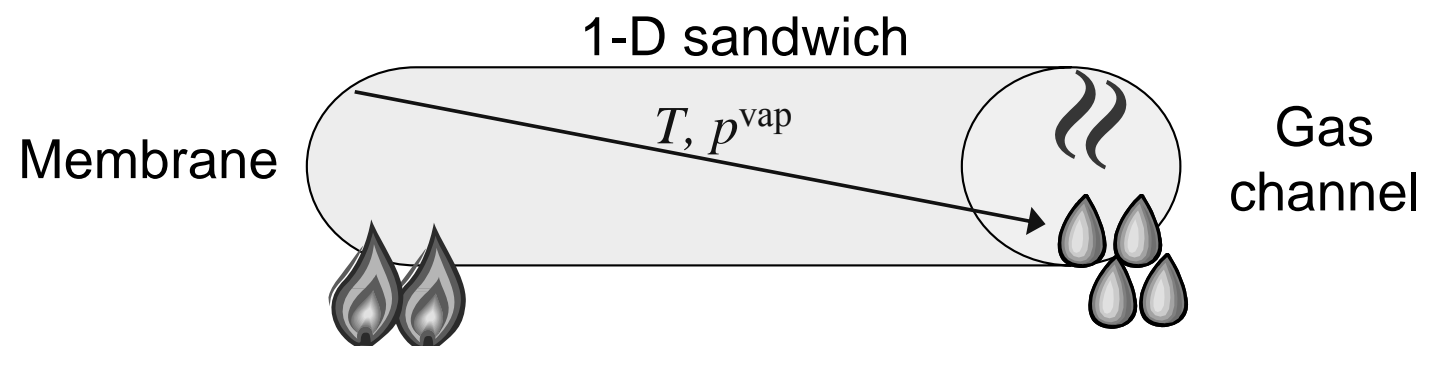

Figure 1. Schematic representation of a heat pipe on the cathode side of the fuel cell. Water is evaporated in the catalyst layer and moves and condenses down the temperature gradient. 


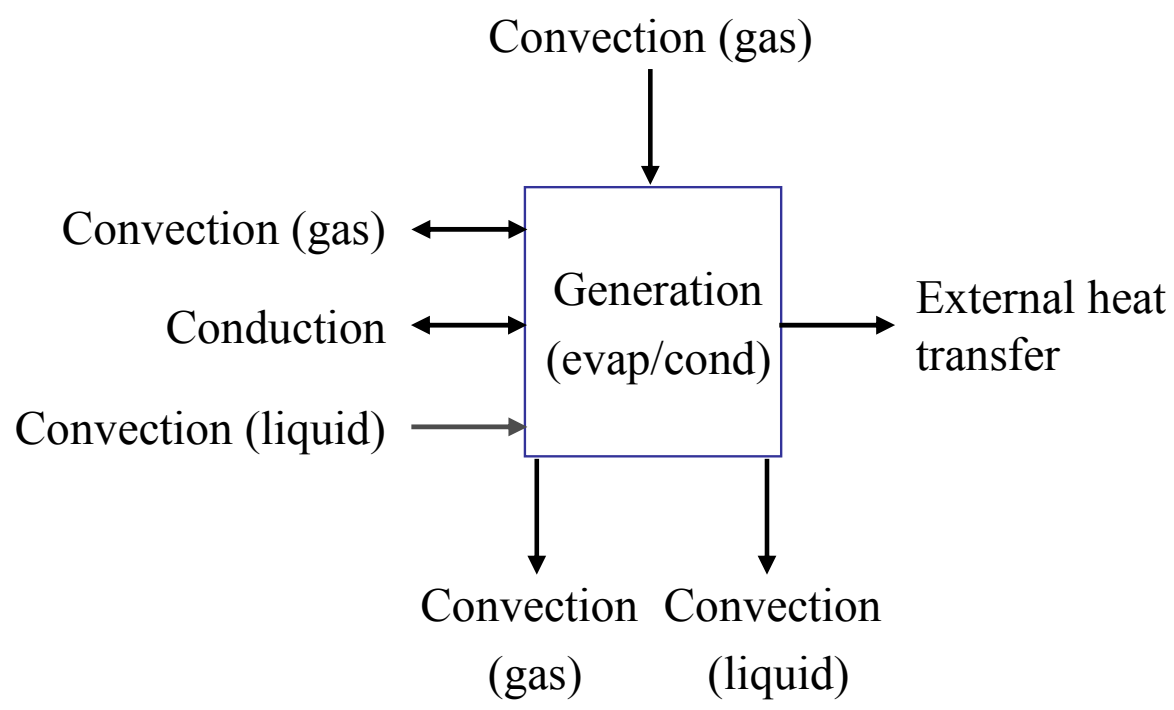

Figure 2. Schematic of the cathode gas channel showing the relevant energy interactions for the temperature boundary condition; the external heat-transfer term is given by equation 6 . The top of the diagram corresponds to the fuel-cell inlet, the bottom to the outlet, the left to the 1-D sandwich, and the right to the coolant stream 


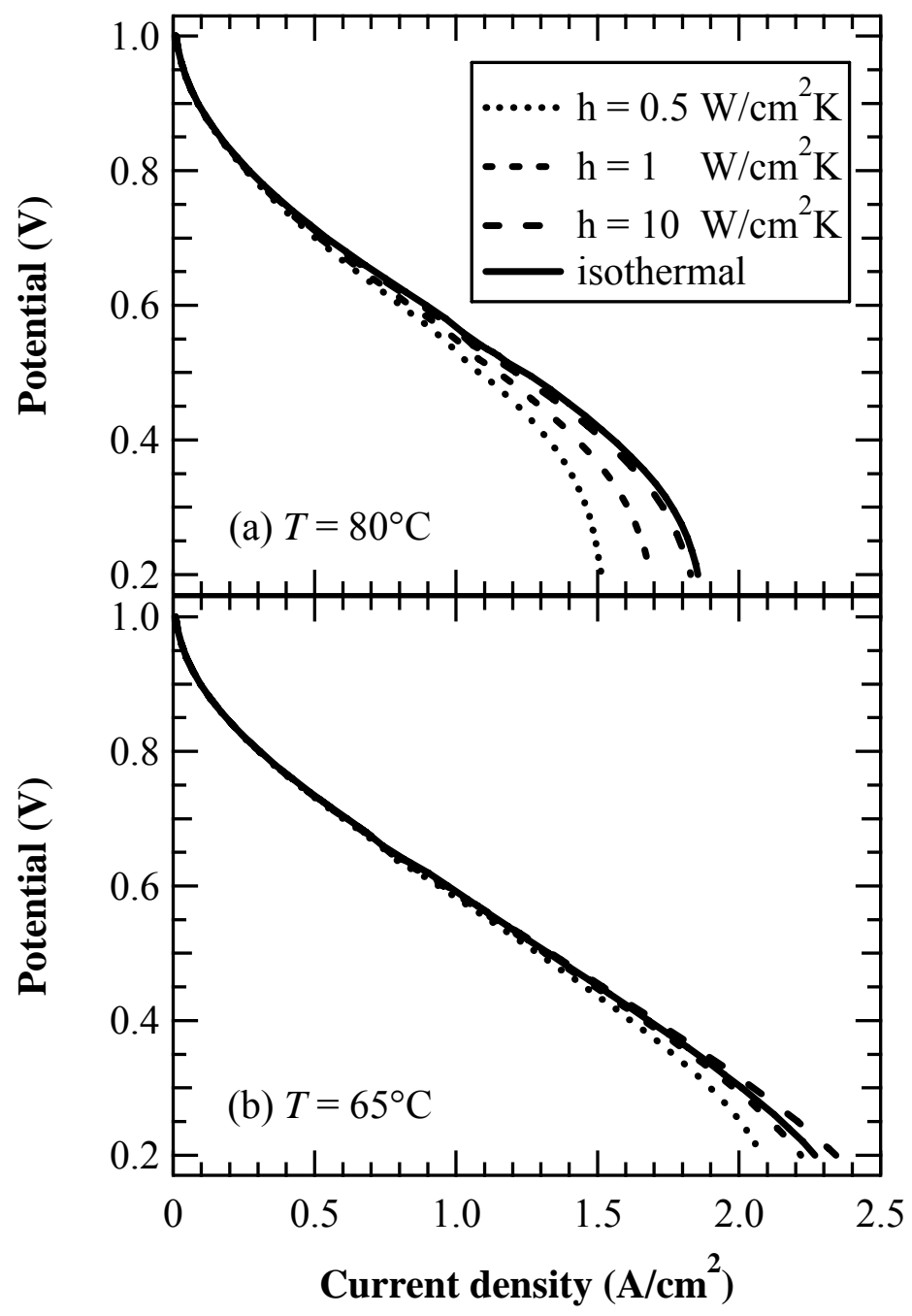

Figure 3. Polarization curves for isothermal operation and three cases of nonisothermal operation with different heat-transfer coefficients. The temperatures for (a) and (b) signify the inlet and coolant temperatures. 


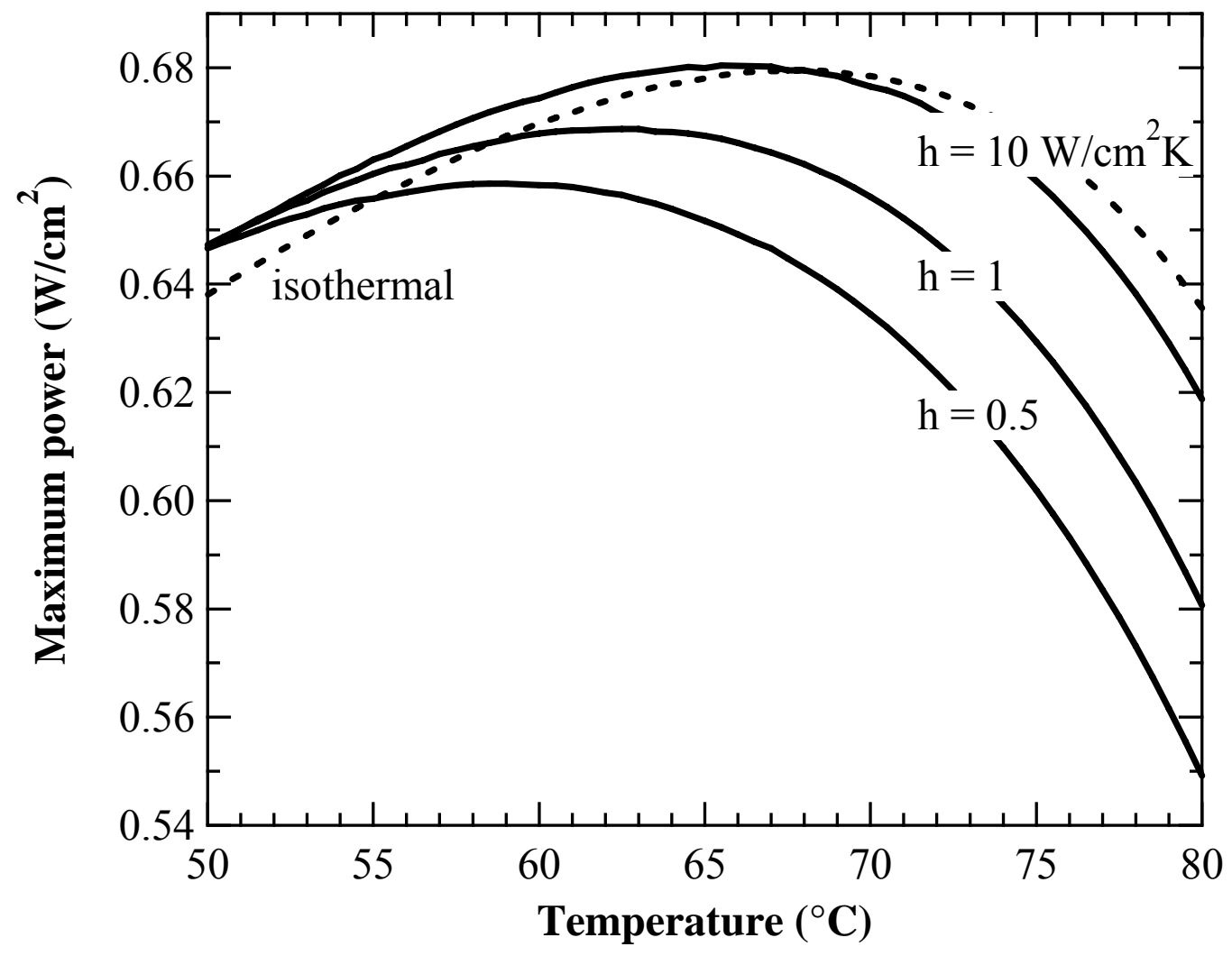

Figure 4. Maximum power as a function of coolant and feed temperature for an isothermal case and three nonisothermal ones with different heat-transfer coefficients 


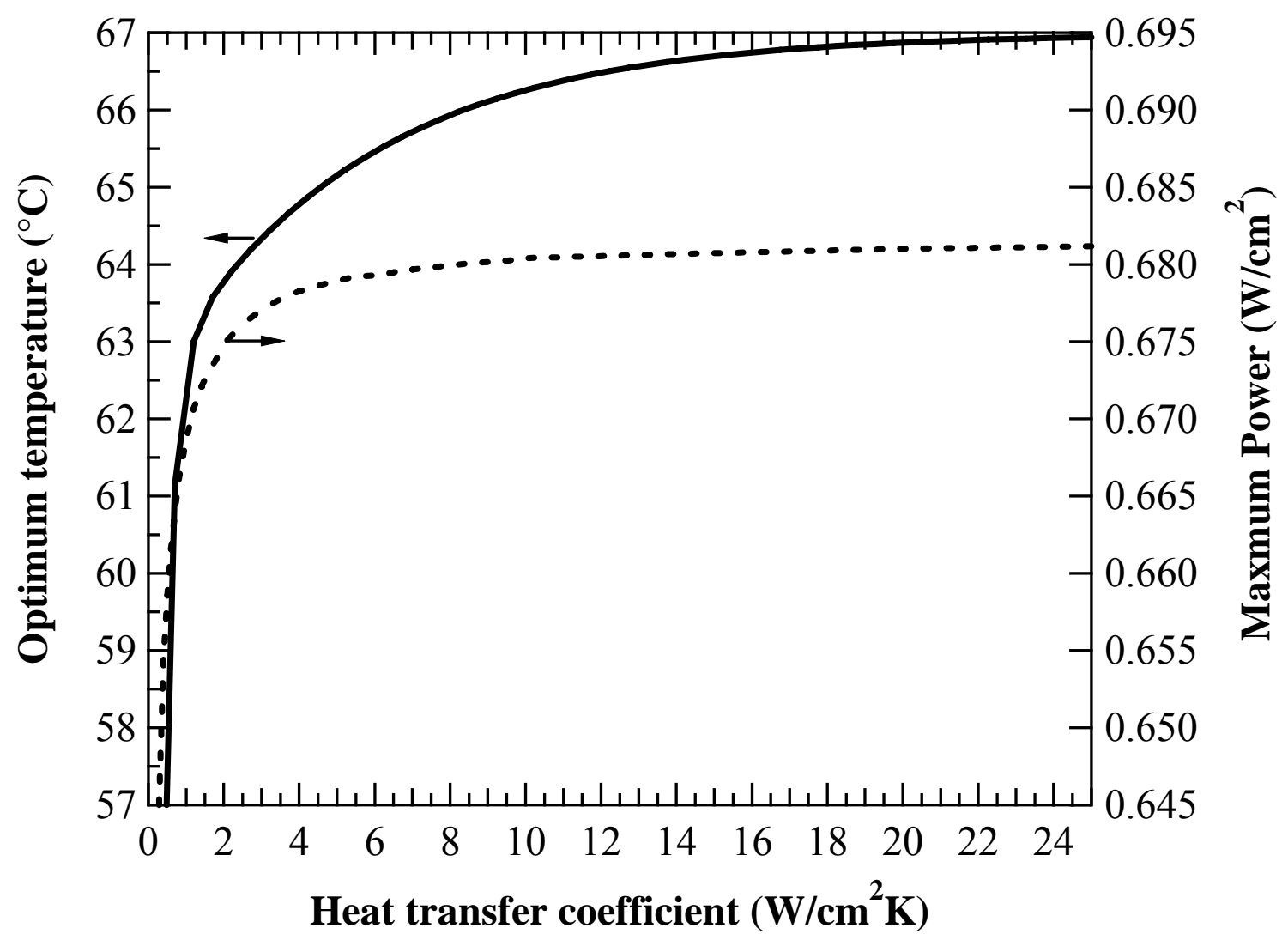

Figure 5. Optimum coolant and feed temperature as a function of heat-transfer coefficient. The optimization is done for the optimum maximum power, which is also given in the figure. 


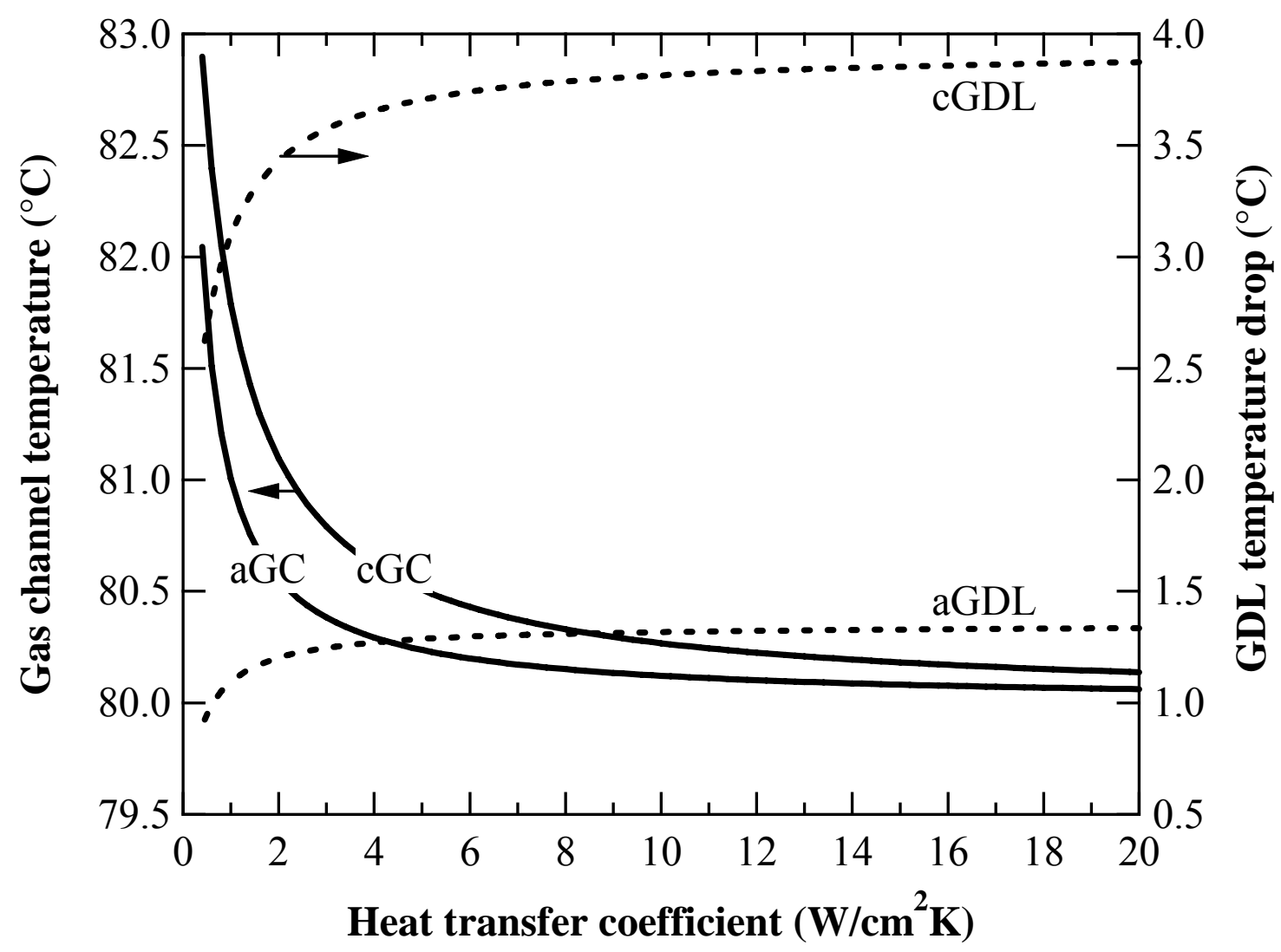

Figure 6. Anode and cathode gas-channel temperature (solid) and GDL temperature drop (dashed) as a function of heat-transfer coefficient for coolant and inlet temperatures of $80^{\circ} \mathrm{C}$. 


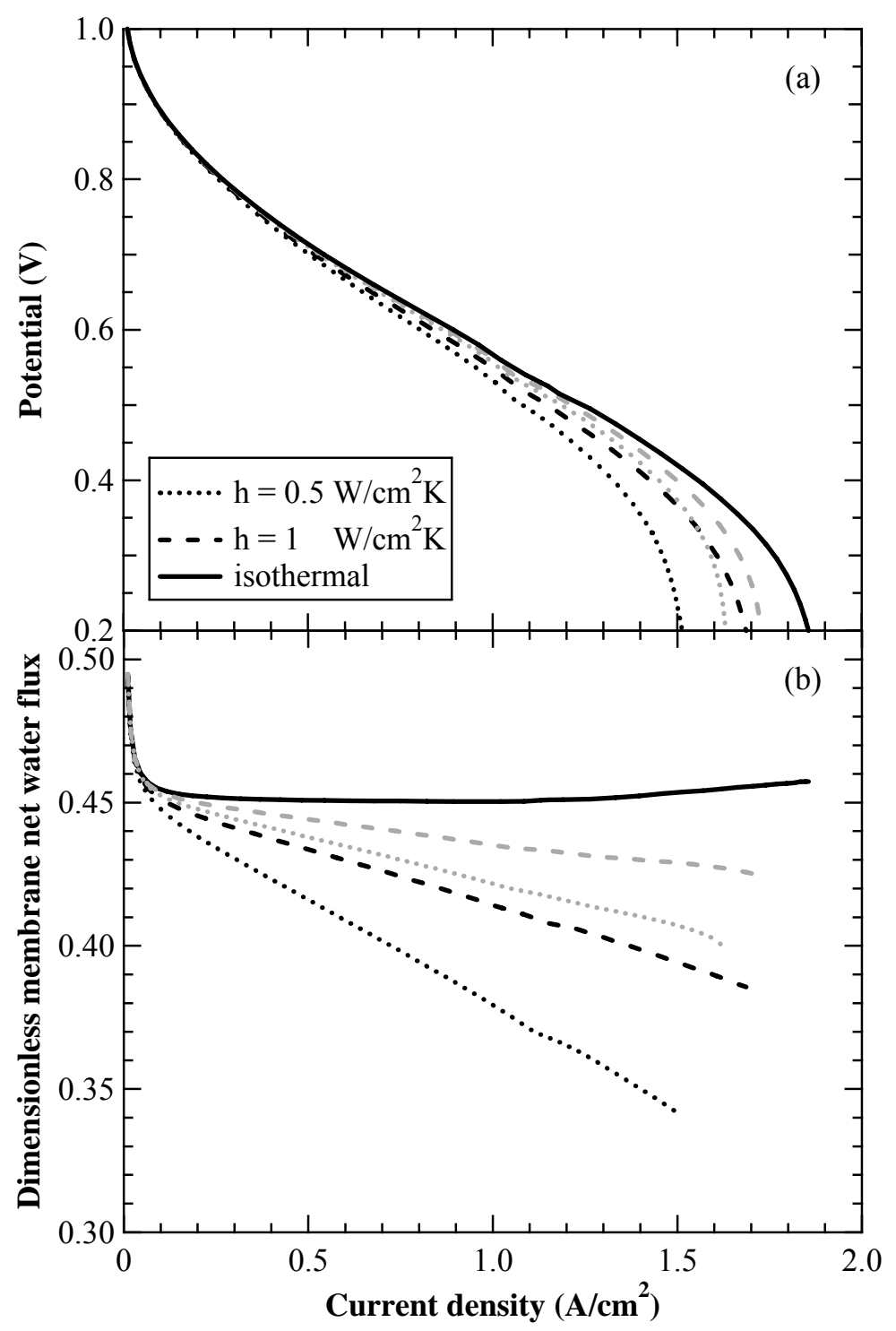

Figure 7. Potential (a) and dimensionless net water flux through the membrane, $\beta$ (b) as functions of current density with coolant and inlet temperatures of $80^{\circ} \mathrm{C}$. The dark lines correspond to the isothermal $\left(T=80^{\circ} \mathrm{C}\right)$ and two nonisothermal cases, and the grayed lines correspond to simulations that account for heat generation and assume the sandwich is of uniform temperature (i.e., infinite thermal conductivities). 


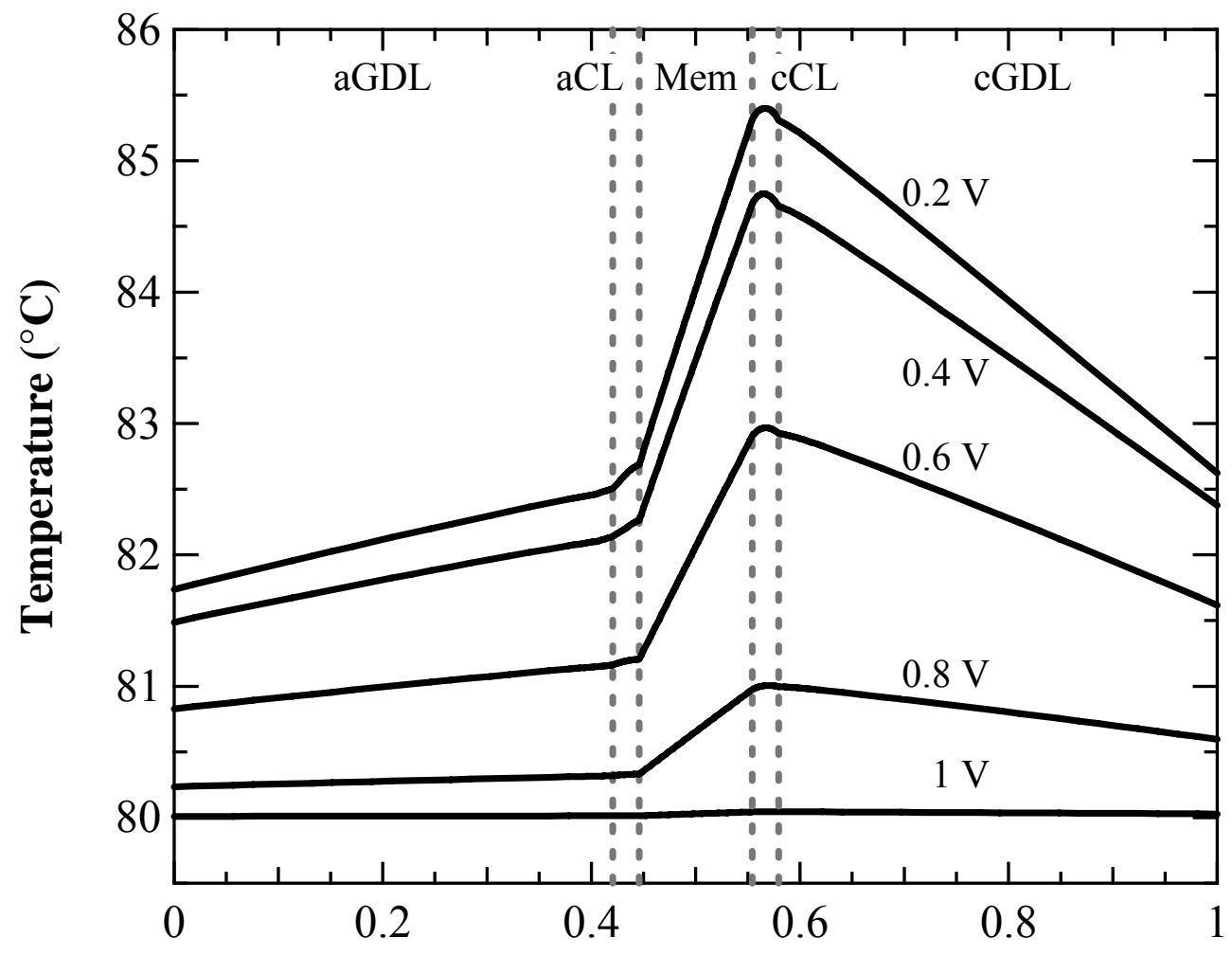

Dimensionless sandwich position

Figure 8. Temperature distribution through the PEFC sandwich at various cell potentials. 


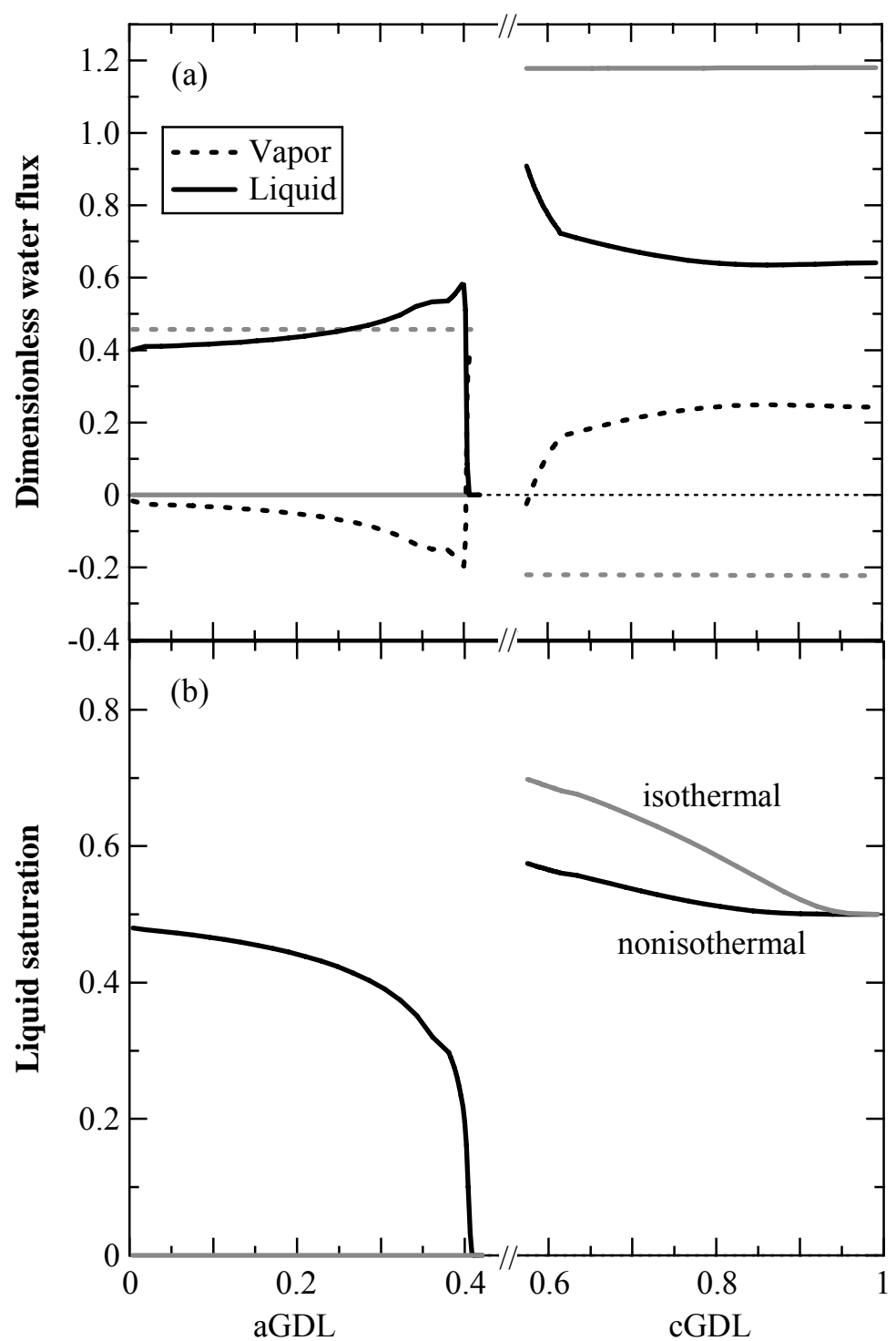

Dimensionless sandwich position

Figure 9. Dimensionless liquid-water (solid) and water-vapor (dashed) fluxes (a) and liquid saturation (b) as a function of position in either the anode or cathode GDL and at a cell potential of $0.2 \mathrm{~V}$. Shown are curves for both the $80^{\circ} \mathrm{C}$ isothermal (gray) and the $\mathrm{h}=0.5 \mathrm{~W} / \mathrm{cm} 2 \mathrm{~K}$ nonisothermal (black) simulations. A positive flux signifies movement from anode to cathode 


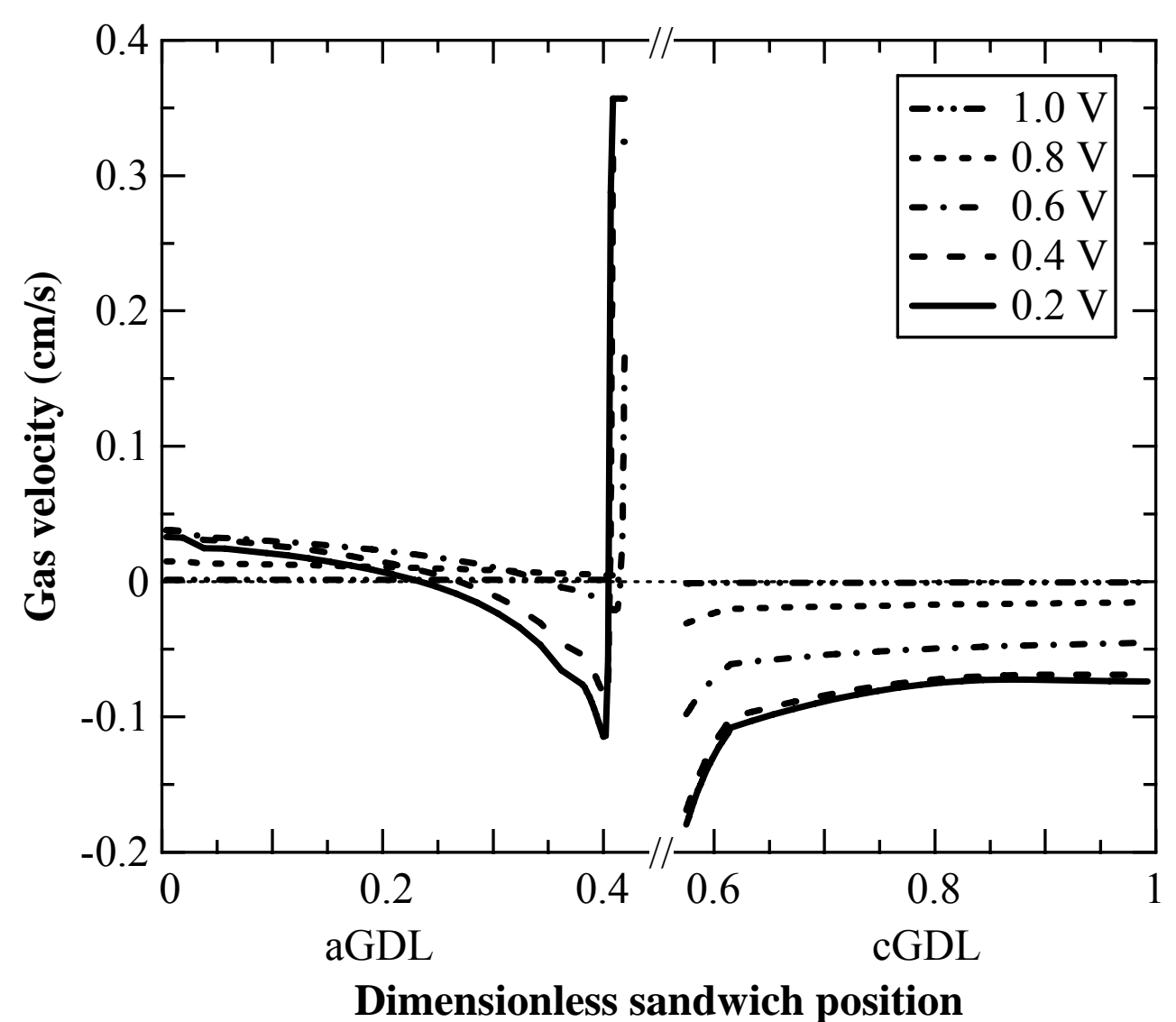

Figure 10. Mass-averaged gas-phase velocity as a function of position in either the anode or cathode GDL, and at various cell potentials. A positive value signifies movement from anode to cathode. For reference, the average values for the isothermal case are 0.55 and $-0.29 \mathrm{~cm} / \mathrm{s}$ for the aGDL and cGDL, respectively. 


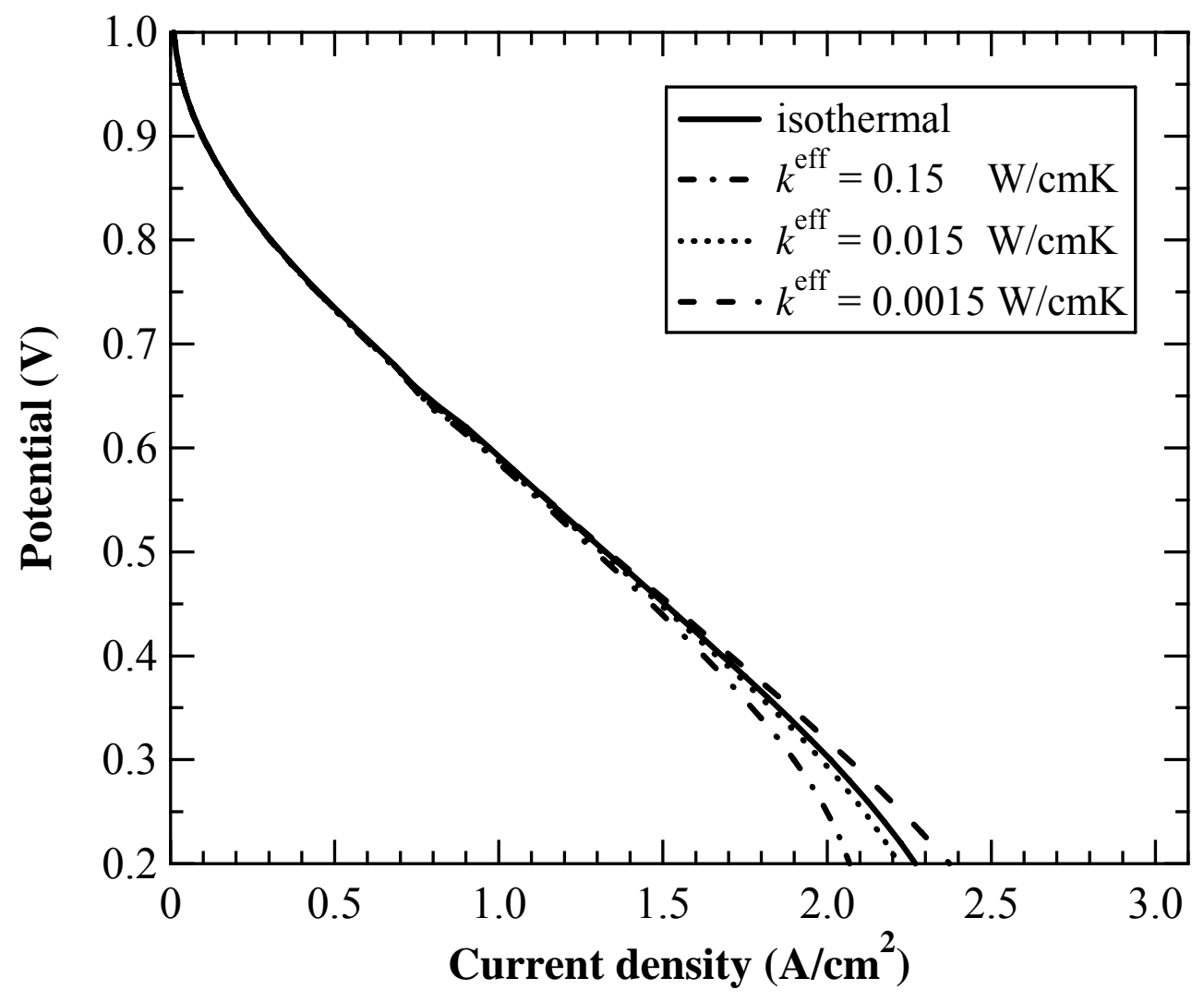

Figure 11. Polarization curves showing the effect of a three-order-of-magnitude change in the GDL thermal conductivities; the other thermal conductivities remain as given in Table I. The temperature is $65^{\circ} \mathrm{C}, h=1 \mathrm{~W} / \mathrm{cm} 2 \mathrm{~K}$, and the isothermal case is shown as a reference. 


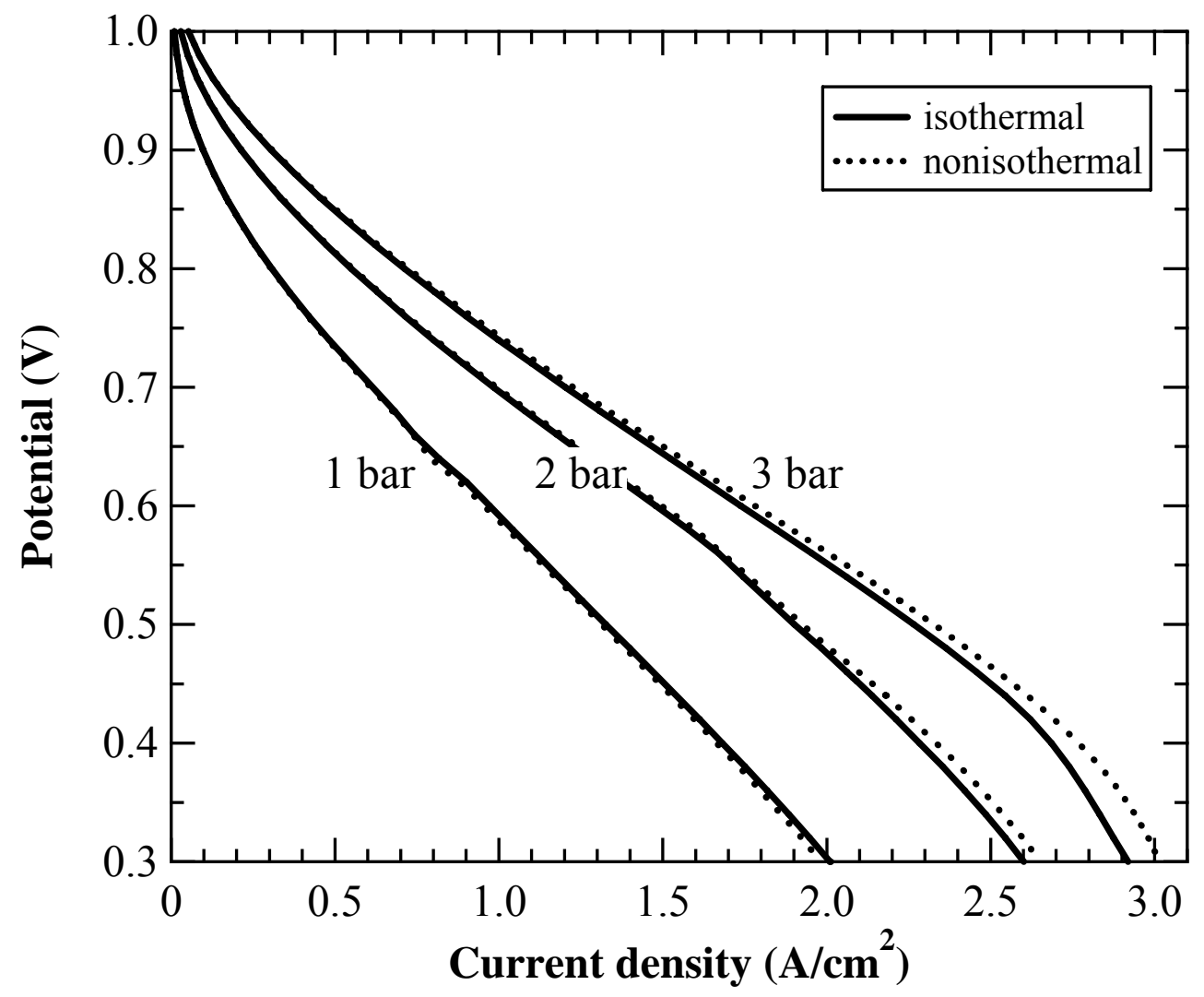

Figure 12. Polarization curves at $65^{\circ} \mathrm{C}$ and $h=1 \mathrm{~W} / \mathrm{cm} 2 \mathrm{~K}$ showing the effect of total gas pressure on performance (anode and cathode pressures are equal). 


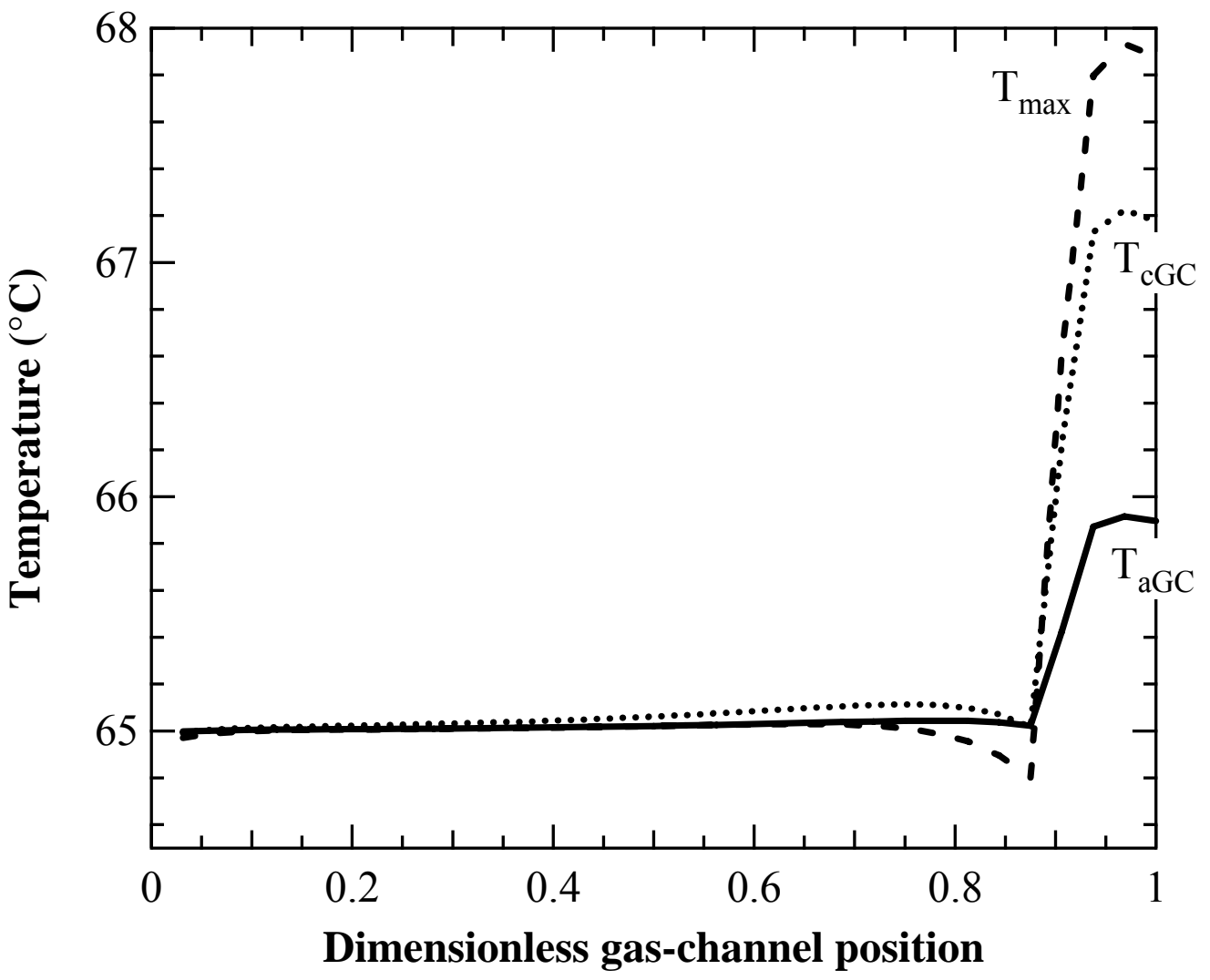

Figure 13. Maximum and cathode and anode gas-channel temperatures as a function of position along the gas channel (the inlet is on the left) using a pseudo 2-D, coflow model with $50 \%$ relative-humidity feeds. The sharp increase in the temperature is associated with liquid-water formation. 